\title{
مفهوم العقل العام بين الحداثة وما بعد الحداثة دراسة في فلسفة السياسة
}

\author{
إعـلــاد \\ آيات عادل زكريا محمد حسن \\ باحثة دكتوراه - قسم فلسفة - شعبة سياسة \\ كلية الآداب - وجامعة حلوان
}

Doi: $10.12816 / 0051451$

مجلة الدراسات التريوية والانسانية ـ كلية التربية ـ جامعة دمنهور

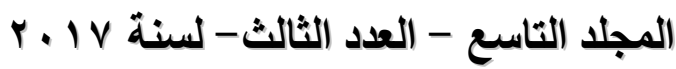




\section{مفهوم العقل العام بين الحداثة وما بعد الحداثة دراسة في فلسفة السباسة}

د.آيات عادل زكريا محمد حسن

Doi: $10.12816 / 0051451$

ملخص:

تحاول هذه الدراسـة الكثف عن طبيعـة العلاقة بين التعدديـة Pluralism

باعتبارها المشكلة السياسية للعصر الحديث - كما يري ليبراليين ما بعد التتوبر وفكرة العقل العام Public Reason كمحاولة لحل هذه المشكلة. فالتعدديـة هي الســة الأساسـية المميـزة للمجتمعـات الديمقراطيـة الحديثـة. والتعدديـة المعقولـة، بصفة خاصة، هي النتيجة الطبيعية لإعمال العقل الإنساني وممارسة الديمقراطية في هذه المجتمعات. ولكن هذا الواقع التعددي لا يسـل قبوله دائمًا، إذ يبدومن الصعب، إن لم يكن من المستحيل، إيجاد قاعدة مشتركة للاتفاق السياسي، حيث يدرك المواطنون أنهم لا يستطيعون التوصل إلي اتفاق أوحتي مجرد التوصل إلي تفهم متبادل علي أساس مذاهبهم الثـاملة المتعارضـة. لهذا يحتاجون إلي التفكير في الأسباب التي يمكن لهم بشـل معقول أن يـدفعوا بها في مقابـل بعضـهم البعض عندما تكون المسائل السياسية محل خلاف.

وفي محاولـة حله لهذه الإشكالية سـي التبار الرئيس للنظريسة السياسية

الليبرالية المعاصرة إلي تقديم تفسير ما بعد تتوبري أوما بعد حداثي للسياسـة في ضـوء فكرة العقل العـام، وأصـبح السؤال المحرك لـه هـو : هـل الحيـاة السياسـية المنظمـة علي أسـاس الإحترام المتبادل، إضـافة إلي سياسـات تهدف إلي تحقيق العدالة، ممكنة أم لا في عالم حديث من الإختلاف العميق حول القيم والعدالة وما هومعقول؛ وكما تسائل رولز هل يمكننا تقديم نظريـة ليبرالبـة تتتاول بجديـة حقيقة التعددية المعقولة؟

وفي الإجابة علي هذا التساؤل الرئيس يقدم العقل العام الكيفية التي يمكن بها للمواطنين في هذه المجتمعات أن يعيشـوا جنبًا إلي جنب في عالم تسوده ए $\leqslant 1$ 
العدالة، ويكثف النقاب عن قاعدة أساسية للاتفاق، تكون مقبولة بالتبادل بحيث يظل من الممكن الحفاظ علي تصسور سياسي قائم علي مبدأ احترام منبـادل.

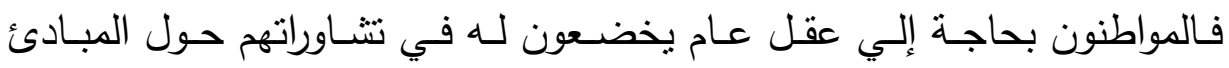
الدستورية وموضوعات العدالة الرئيسة.

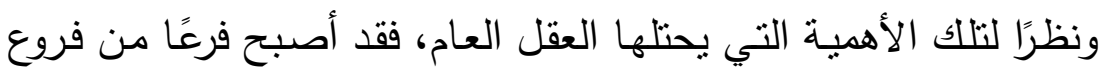

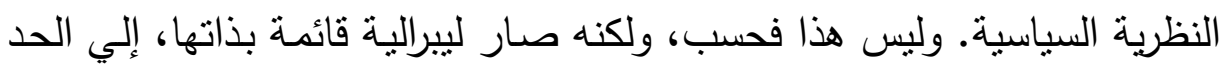

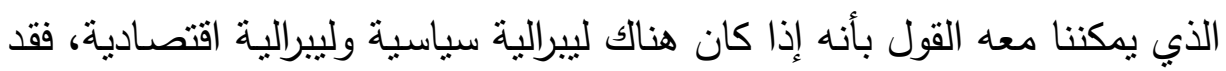

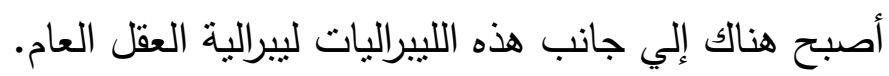

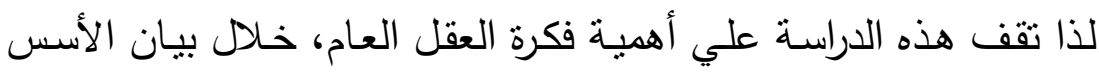

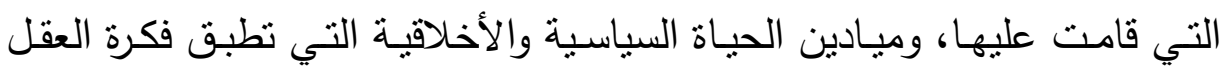

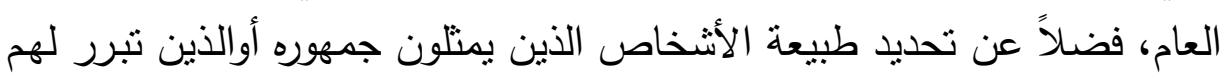

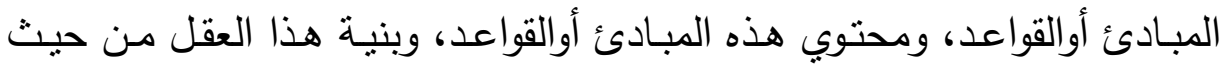

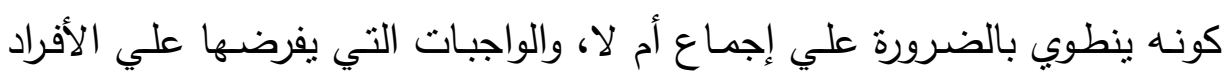
وفي أي جوانب حياتتا تطبق مطالب العقل العام •

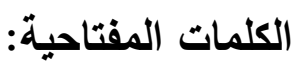

العقل العام - المجال - الجمهور - المحتوي - البنية - الواجبات

$$
\text { رولز - هابرماس - جاوس. }
$$




\section{مقدمة}

يتطلب العقل العام أن تكون القواعد السياسية أوالأخلاقيـة التي تنظم حياتتا

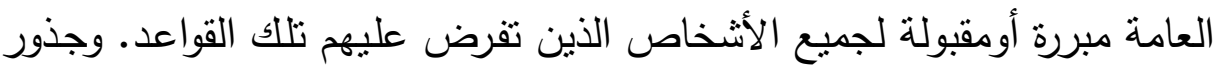

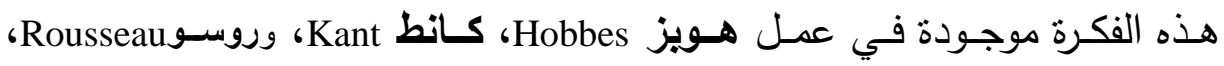

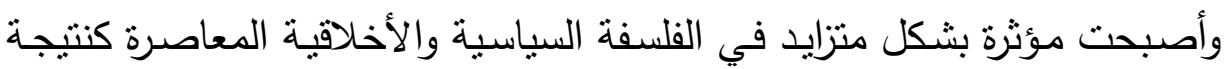

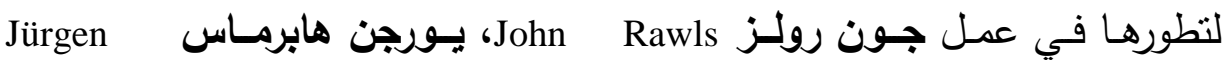
Habermas

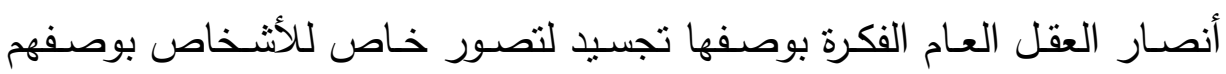

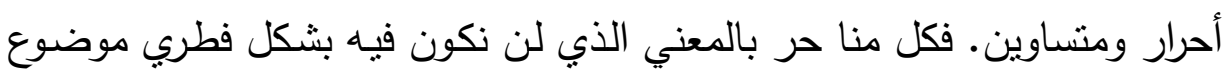

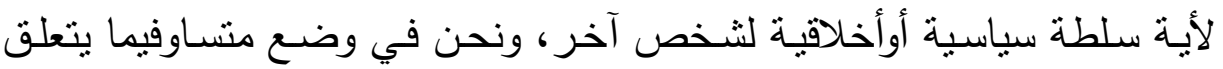

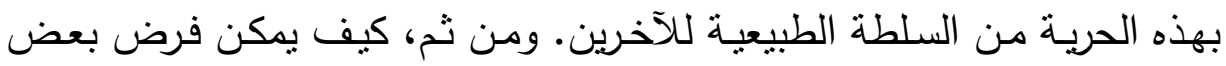

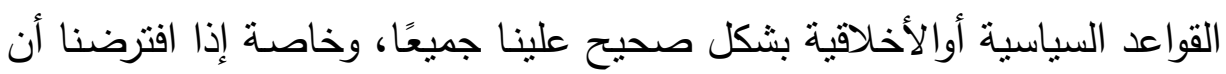

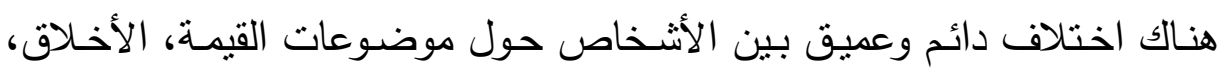

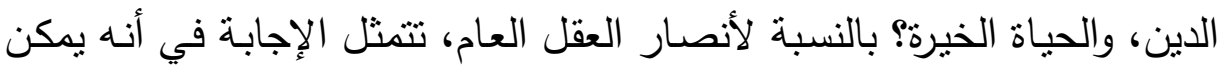
فرض هذه القواعد بشكل صحيح علي الأشخاص عندما يمكن تبرير القواعد

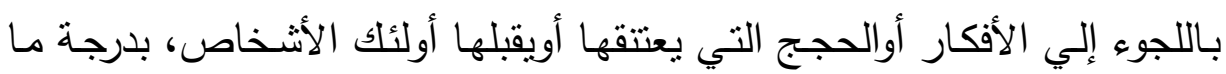
من المثالية.

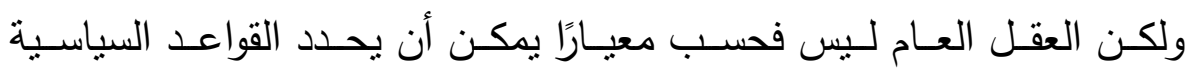

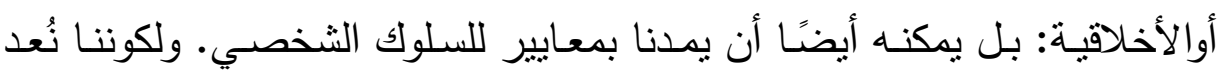

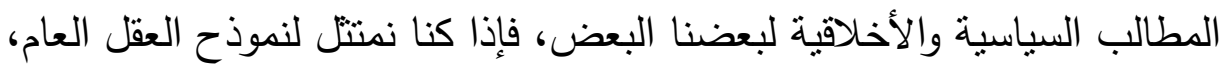

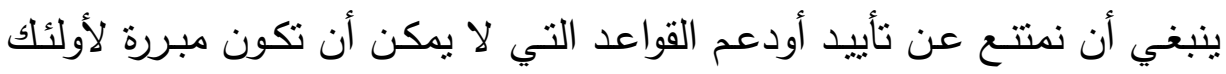

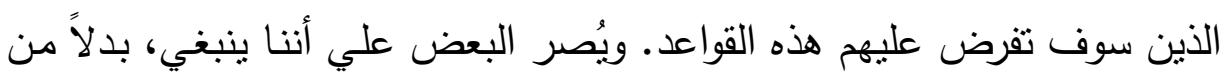

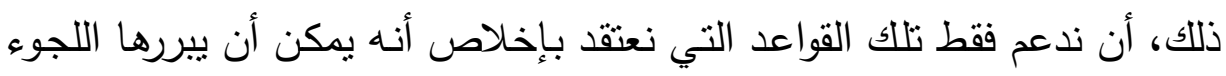
بشكل ملائم إلـي اعتبـارات عامـة أومشتركة - منهـا علي سبيل المثنال، القيم 
السياسية المؤيدة بشكل واسع مثل الحريـة والمساواة - وأن نمتتع عن اللجوء إلي الي

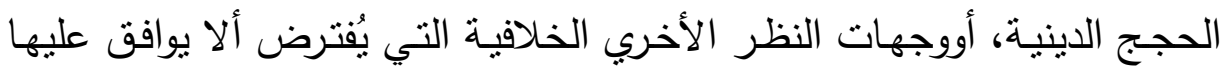

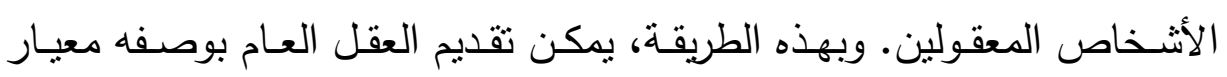
لتحديــ القواعد، القـوانين، المؤسسـات، وسـوك المـواطنين منفردين والمـوظفين الحكوميين.

وبيدوأن فكرة العقل العام تشـل موضـعًا وسطًا بين اثتين من أكثر معابير التقييم المألوفة في الفلسفة السياسية والأخلاقية. فمن ناحية، هنالك معيار الموافقة وسطة Consent

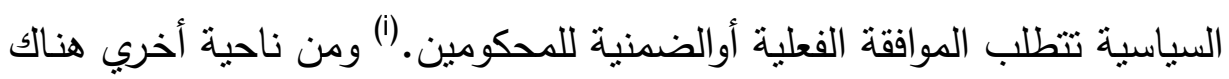

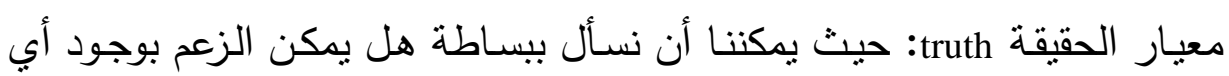

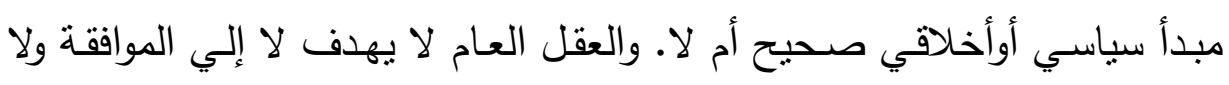

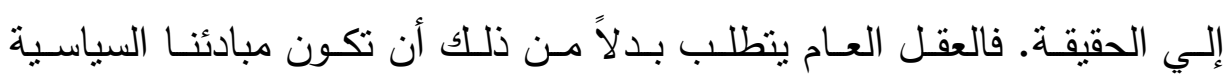
أوالأخلاقية مبررة، أومقبولة بشكل معقول، لجميع الأثخاص الذين تطبق عليهح

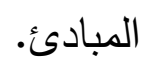
تقدم هذه الدراسـة خمس إجابات مختلفة عن هذا السؤال، والتي يمكن أيضًا

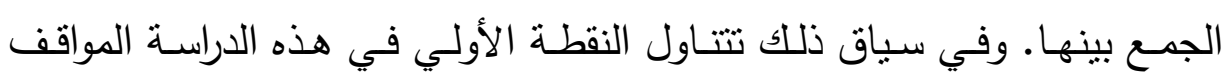
المتنافسة المتعلقة بالأساس المنطقي الضمني للعقل العام. وتحدد النقطة الثانية

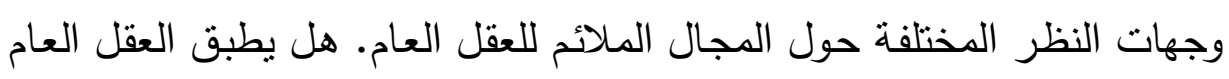

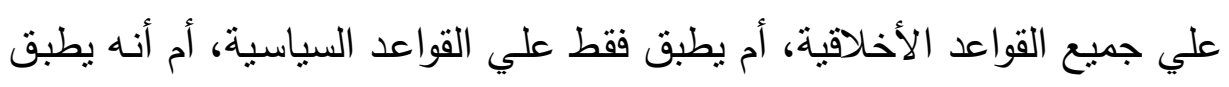

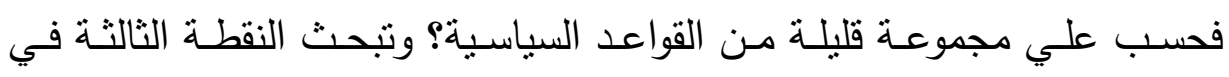
السؤال عن جمهور العقل العام: لمن ينبغي أن تكون قواعدنا مبررة لكي تكون الكئن

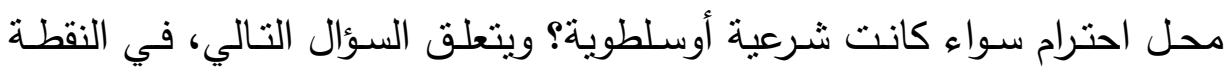

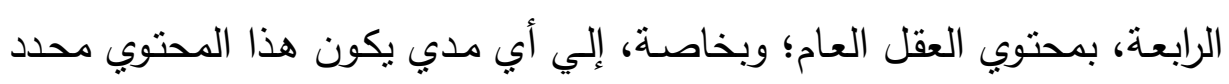

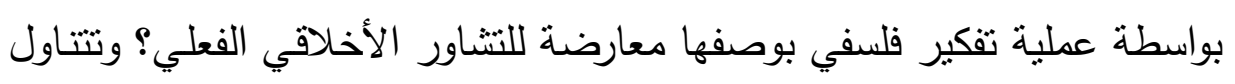


النقطة الخامسة بنية العقل العام، مع التركيز بشكل خاص علي ما إذا كان العقل

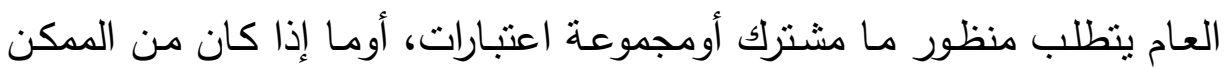

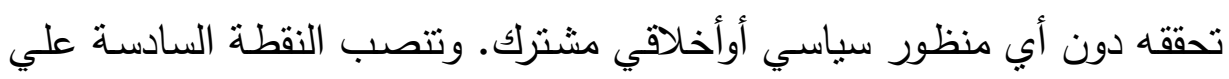

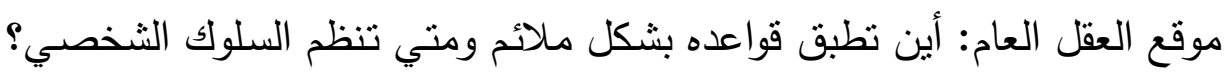

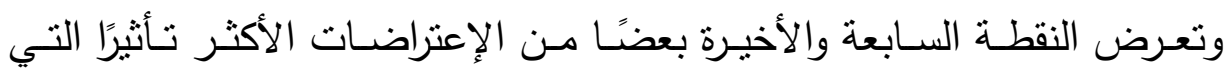
تتاضل ضد فكرة العقل العام .

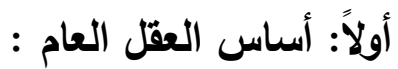
يفترض جميع أنصار العقل العام أن هناك اختلاف عميق ويصعب معالجته بين بعض الأشخاص وأن هذا الاختلاف ليس ببساطة نتيجة للاعقلانية، التحيز ،

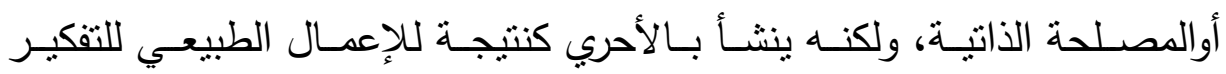
الإنساني في ظل ظروف ملائمة بشكل معقول. ويبدوهذا الافتراض حول التعددية

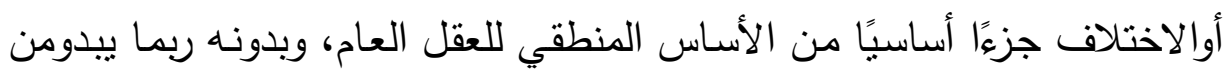

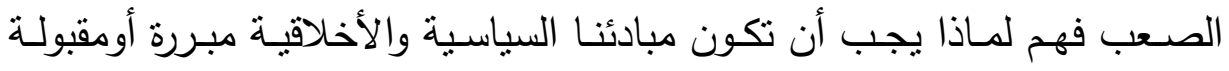
للآخرين، بوصفها معارضـة ببساطة للحقيقة أوالصواب. والتصور الأكثر تأثنرًا

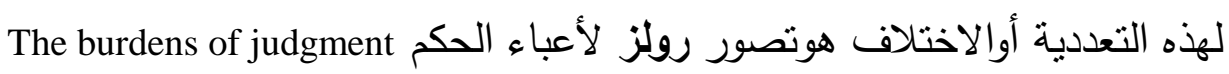

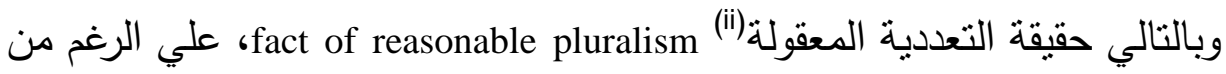
أن هذا التصور خلافي، وعرضة للنقد الواسع (iii) ويقدم بعض الفلاسفة فكرة العقل العام، أوالاستخدام العام للعقل، بوصفها جزء وعرضه للهُ

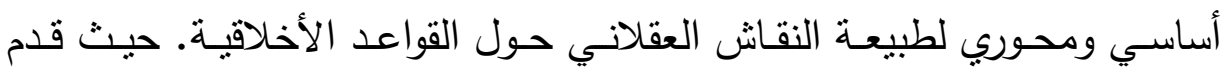

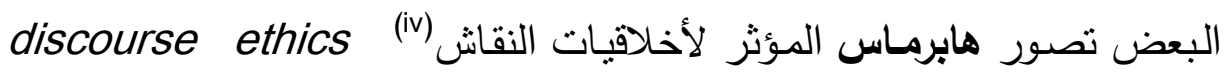
بوصفه يؤسس بهذه الطريقة تصور عقل عام. ووفقًا لوجهة النظر هذه، تؤسس شرعية القواعد السياسية والأخلاقية فقط خلال ممارسة مثالية وبين ذاتية للنقاش. وفقط عبر عملية منطقية غير قسرية وشاملة، حيث يكون جميع المشاركين في وضع متساو، يمكن أن تتشأ بإخلاص قواعد شرعية علي نحوبين ذاتي. ومن ثم 
يعلن هابرماس أن قاعدة أخلاقية تكون » شرعية فقط في الحالة التي سوف يقبل

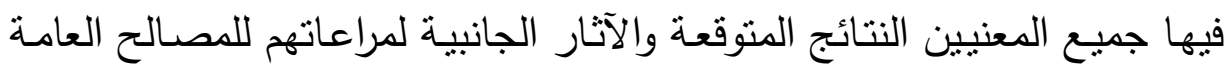
والتوجهات القيمية لكل فرد دون إكراه « (v)

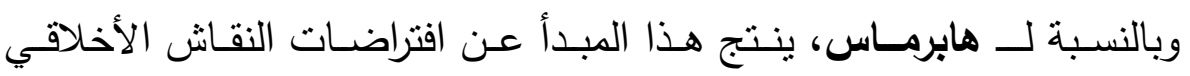
العقلاني، ولذلك فمعني أن نتارك في حجة سياسية أوأخلاقية معقولة مع الآخرين

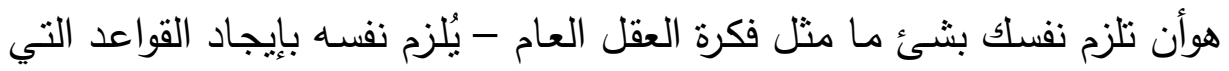

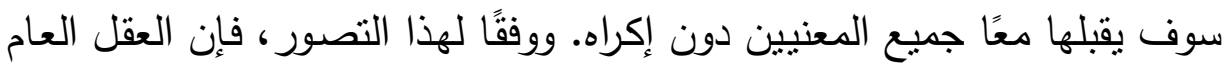

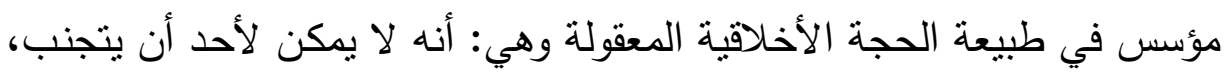

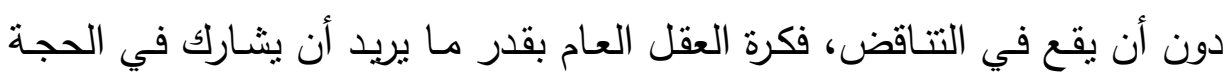

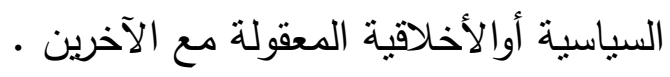
وعلي الرغم من أن تصور هابرماس لأخلاقيات النقاش مؤثر فيما بين أولئك الته

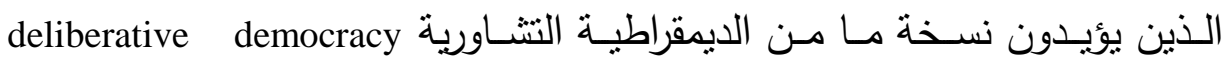

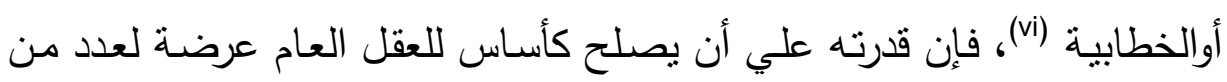

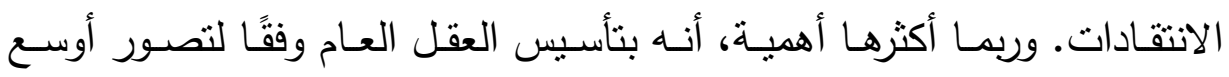

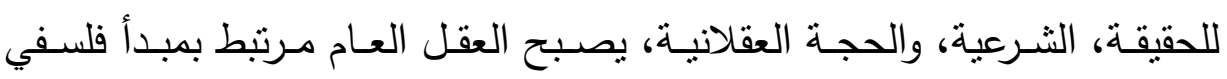

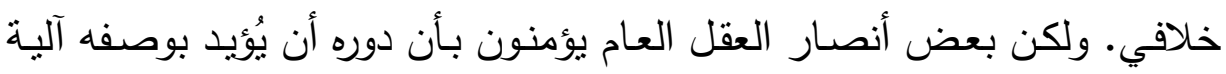
تبرير فيما بين الأشخاص الذين يختلفون بمعقولية حول القضايا الفلسفية والقضايا

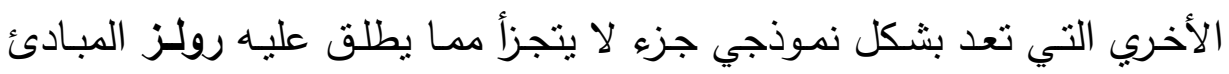

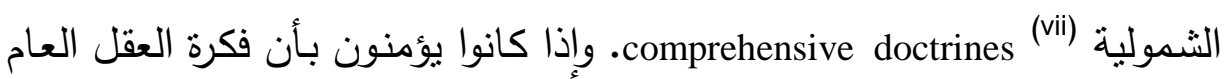

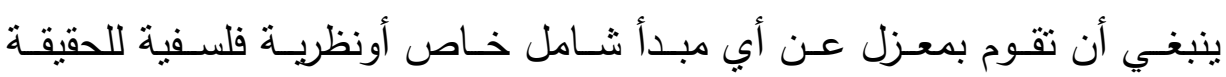

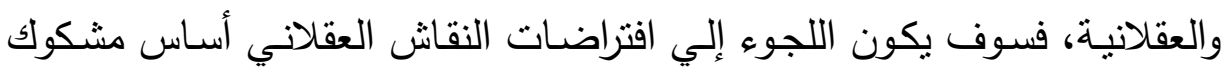

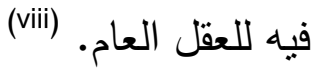
ويبرهن آخرون، وأكثرهم وجاهه جاوس، علي أن فكرة العقل العام تتشـأ عن

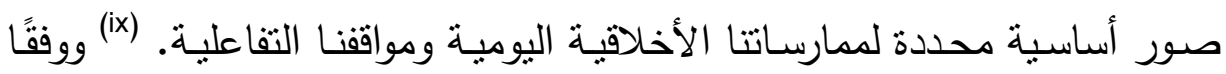


لوجهــة النظـر هـذه، تتضـمن الأخـلاق الاجتماعيـة نـوع خـاص مـن علاقــة

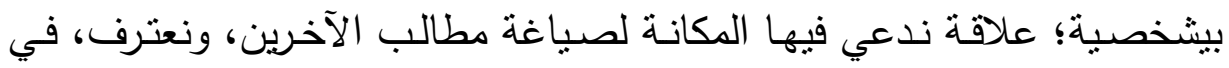

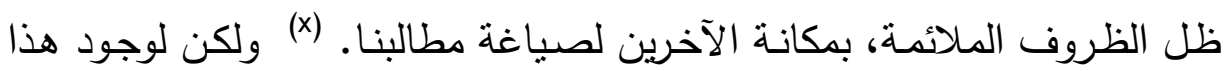

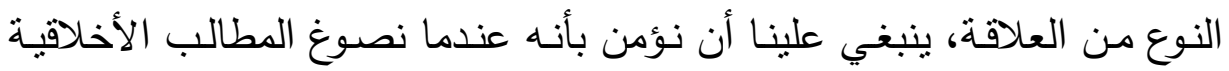

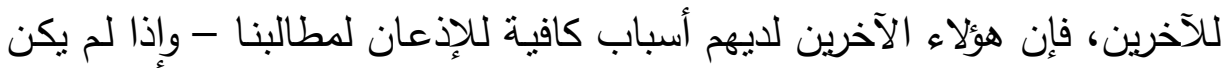

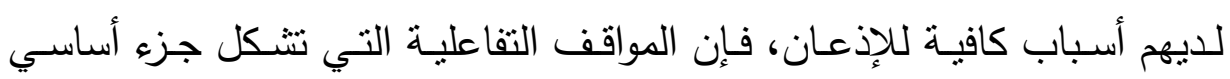

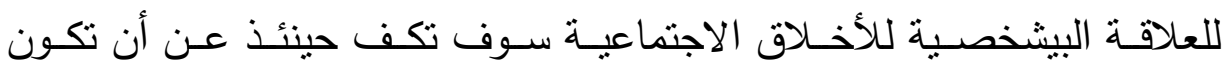
مفهومة. (xi) وكما يؤكد جاوس، إذا كان لاي الأشخاص المختلفين أسباب مختلفة

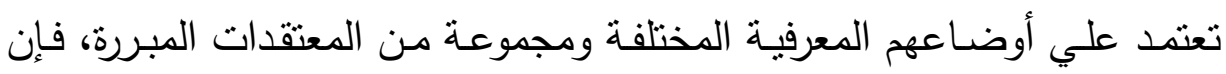

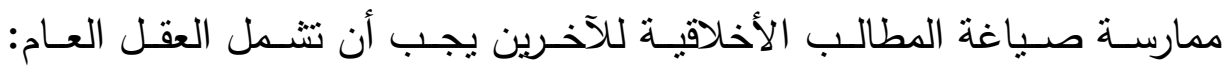
فالمطالب الأخلاقية التي نصوغها للآخرين يجب أن تكون مبررة لهم باللجوء إلي الأسباب التي لديهم، وليس ببساطة خلا اللجوء إلي الحقيقة كما نراها نحن.

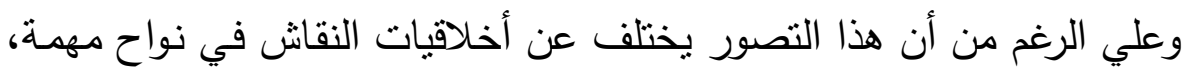

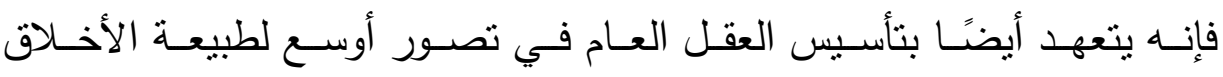

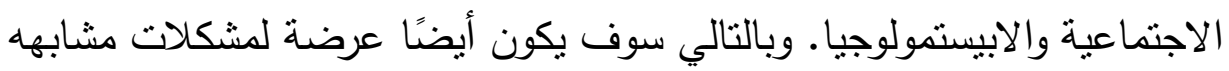

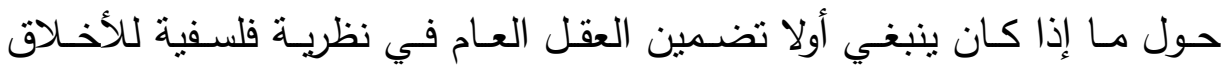
والابيستمولوجيا مثيرة للجدل وشاملة. ووفقًا لإحدي وجهات النظر السائدة، ذات الأصول الكانطية والروسية، نتطلب الحرية أن نطيع فقط تلك القوانين التي سوف نمنحها لأنفسنا بعقلانية. فأن تكون

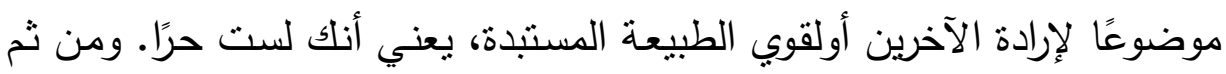

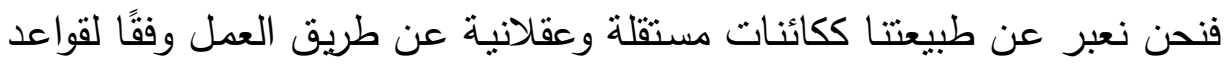

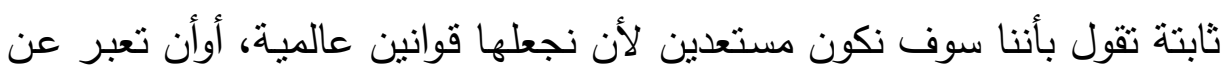

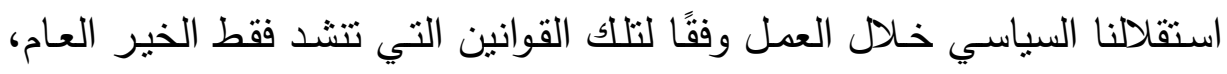

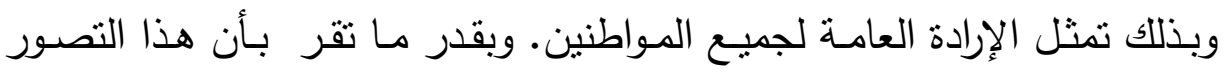


للاستقلال في غاية الأهمية، فإن الاستقلال يجب أن يمدنا بالتالي بالأساس للعقل العام.

وبضـمان أن مبادئنسا السياسية أوالأخلاقيـة مبـررة أومقبولـة بمعقوليـة بالنسـبة

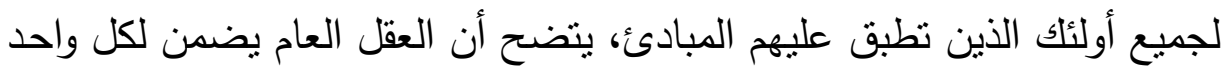

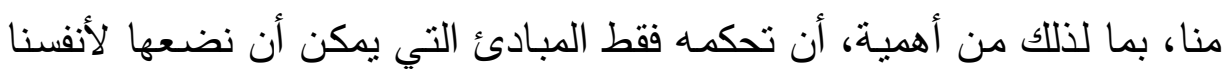

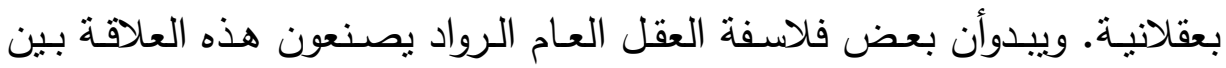

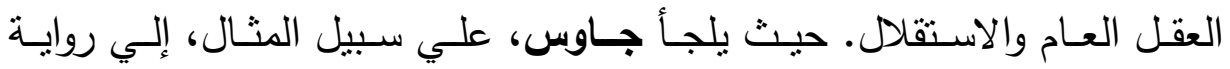
روسوحول أن المشكلة الأساسية التي عني العقد الاجتماعي بأن تكون الحل هي الإسي

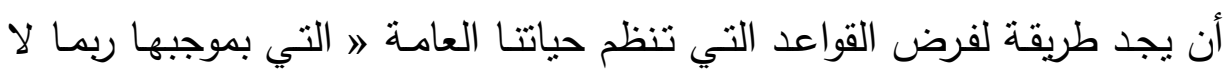
يزال كل شخص يطيع نفسه وحدها، بينما يوحد نفسه مع الجميع، ويبقي حرًا كما

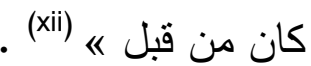
ولكن المدي الذي يمكن اللجوء فيـه للاستقلال، أن يبـرر، مـن تلقاء نفسـه،

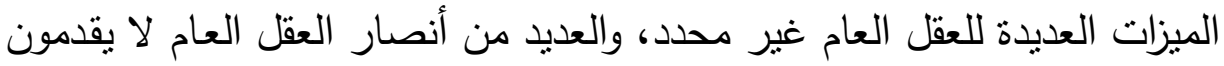

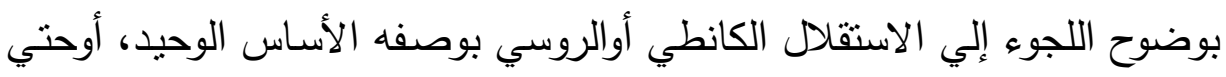

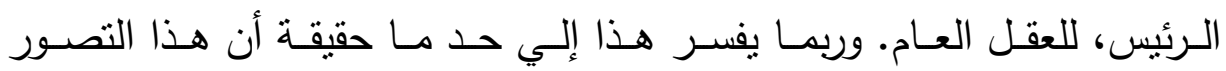

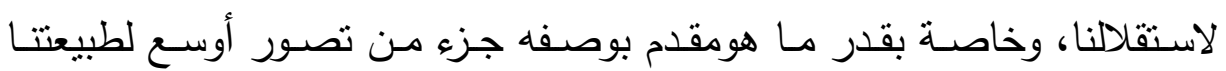
ككائنات عقلانية، هوتصور خلافي وعرضة لاختلاف معقول. (xii)

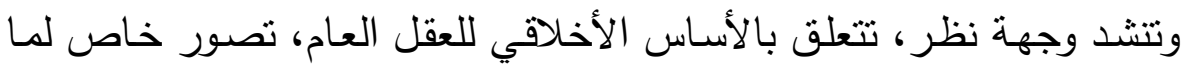

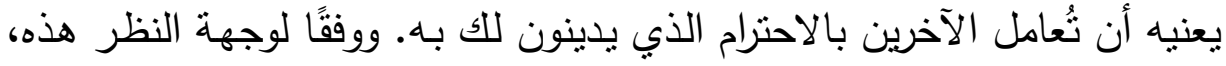

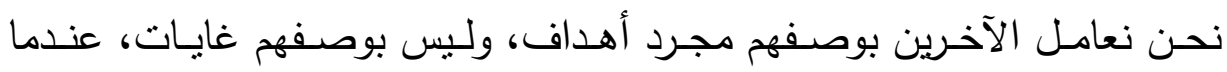
نكرههم علي أسـاس الأسباب أوالحجج التي لن يقبلونها بمعقوليـة. فعلي سبيل

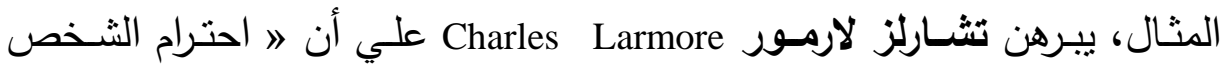

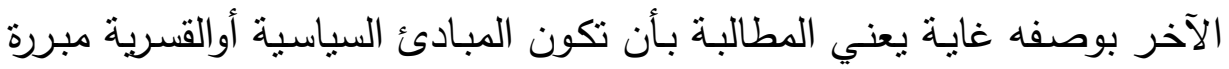

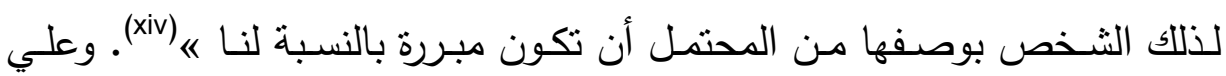


العكس من ذلك، 》إذا حاولنا أن نحدث امتتالاً لقاعدة مـا للسلوك بشكل فردي خلال التهديد بالقوة، فسوف يعني هذا أننا نعامل الآخرين بوصفهم مجرد أهداف، بوصفهم موضوعات للإكراه، وليس أيضًا بوصفهم غايات، يشـاركون بمقدرتهم

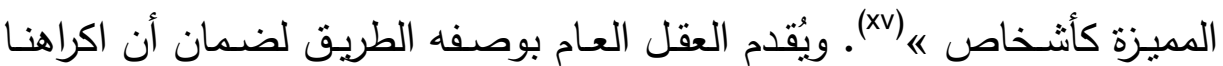

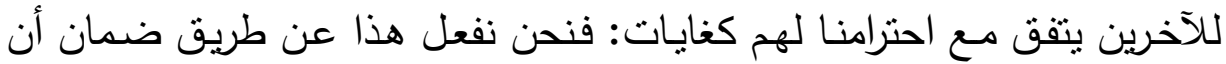

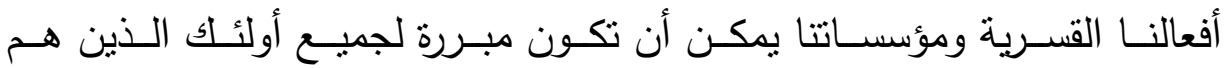
موضوعات للإكراه. ويبرهن البعض علي أن العقل العام يتضمن بالتالي تسليم

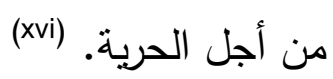

وبتأسيس العقل العام علي تصور ما لكيف يمكن أن يكون القسر هوالاحترام المناسب، فإن وجهة النظر هذه تقيد مجال العقل العام بطرق ربما تبدومزعجة.

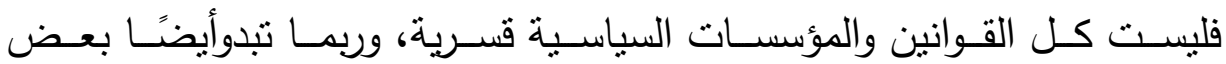
المؤسسات السياسية غير القسرية موضوعات مناسبة للعقل العام. فعلي سبيل المثال، سوف تبدوموضوعات مثل أي صور الزواج، إن كان أب منها، ينبغي أن

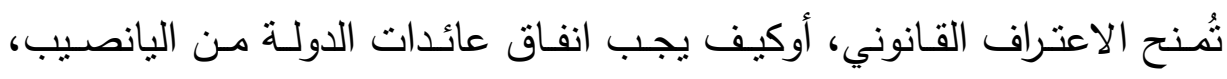

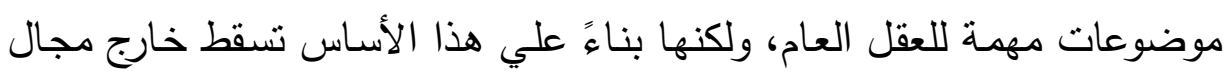

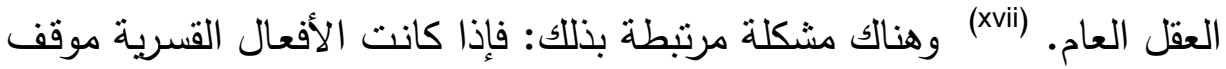
استثنائي في حاجة إلي تبرير عام، فإنها ربما تجعل من الصعب، أوحتي من بن المستحيل، بالنسبة للدولة أن تضمن حينئذ بشكل شرعي الأهداف العديدة التي في لئي نظرت إليها بأنها مسموح بها علي نطاق واسع. (xvii)

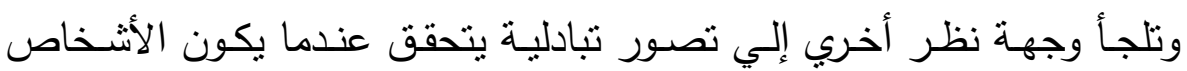

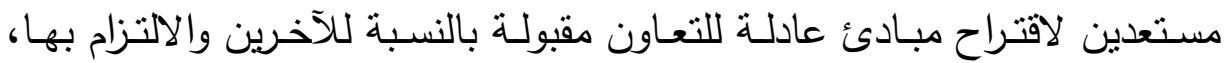
شريطة أن يكون هؤلاء الآخرين مستعدين أيضًا لذلك. (xix) ويقترح رولز أن يكون لئن الدور الأول لمعيار التبادل هذا 》 كما عبر عنه في العقل العام ... هوتحديد طبيعة العلاقة السياسية في نظام ديمقراطي دستوري بوصفه نظام صداقة مدنية 
ه(xx). حيث قدم رولـز العقل العـام بوصفه جزء مـن فكرة الديمقراطيـة نفسـها، وخاصـة العلاقة في مجتمع ديمقراطي بين مواطنين أحرار ومتسـاوبن.(xxi) فوفقًا لوجهة النظر هذه، اتتحدد فكرة العقل العام في المستوي الأعمق للقيم السياسية والأخلاقية الأساسية التي تحدد علاقة الحكومة الديمقراطية الدستورية بمواطنيها وعلاقتهم ببعضـهم البعض. وبايجـاز ، يتعلـق العقل العـام بكيفيـة فهم العلاقـة

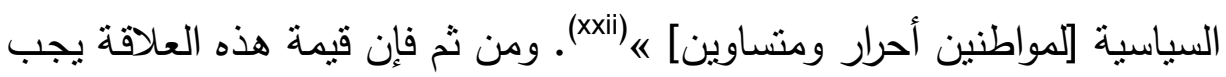
أن تمدنا علي الأقل بجزء من الأساس الأخلاقي للعقل العام.

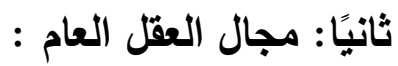

مـا هومجـال العقل العـام؟ ومــا هـي موضـوعات أوميـادين الحيـاة السياسـية والأخلاقية التي تطبق فكرة العقل العام؟ وفقًا لتصسور رولـز المؤثر ، فإن فكرة

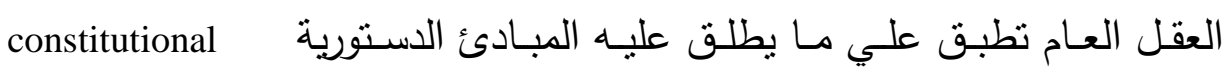
essentials ديمقراطي ليبرالي، 》 وليس بوجه عام علي جميع التساؤلات التي يتم تسويتها عن

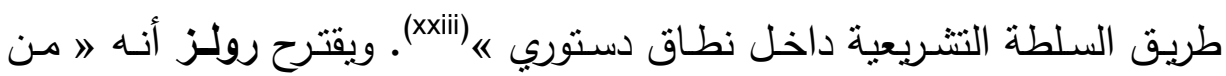

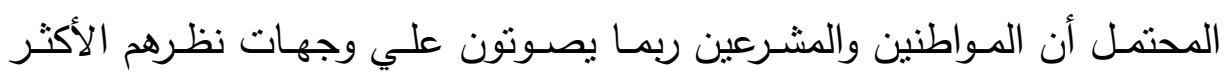

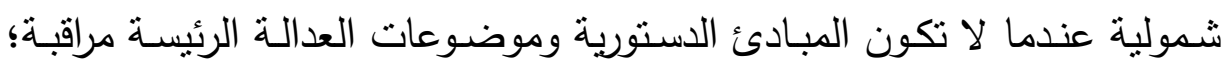

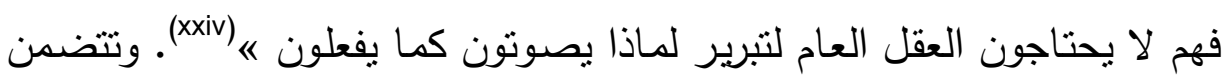

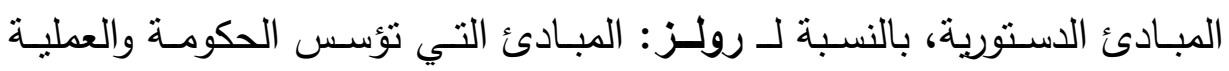
السياسية ( مثناً، القواعد التي تحدد كيف بصوتون، بالنية وما إذا كان نظام برلماني

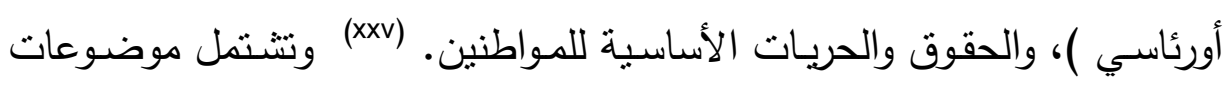

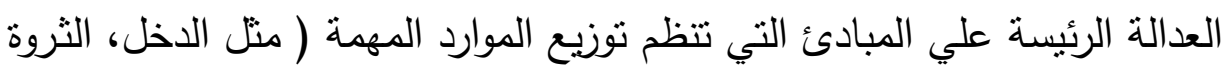
) دون تغطية قائمة الحقوق والحريات الأساسية.(xxvi)

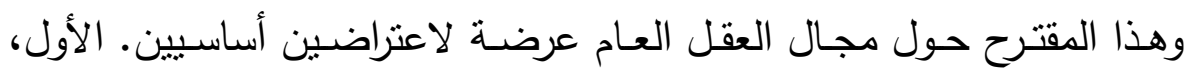

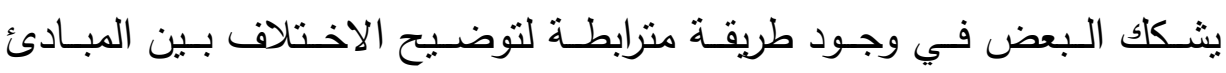


الاستورية وموضوعات العدالة الرئيسة من ناحية، وموضوعات التتريع السياسي

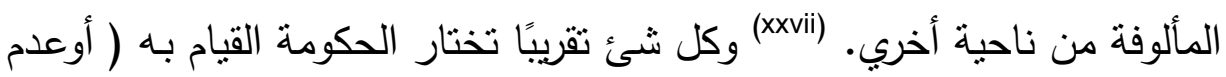

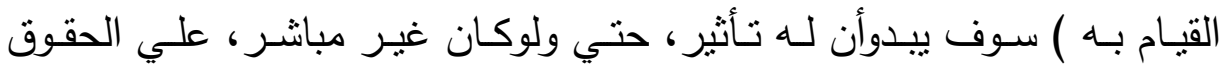

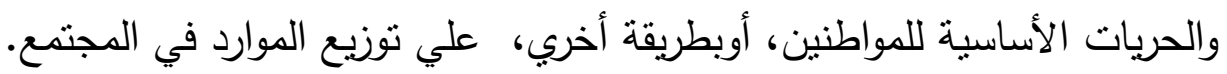

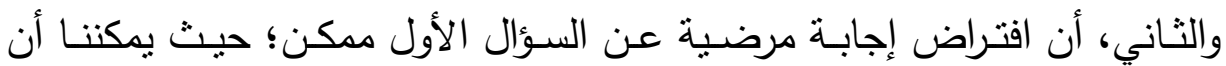
نسأل لماذا ينبغي تقييد العقل العام بالطريقة التي يفترضها رولزب؟ ولماذا لا يمتد

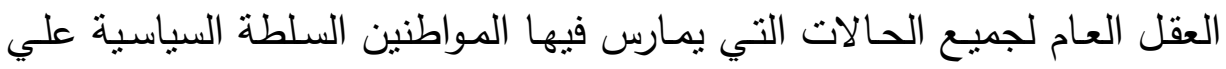
بعضهم البعض؟ لا يقدم رولز إجابة منطورة عن هذا السؤال، علي الرغم من

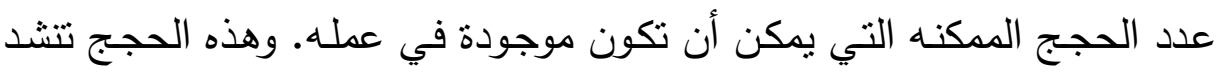

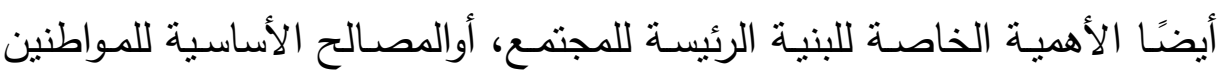
basic interests of citizenS قادرة علي تعميم إجابة واحدة قاطعة علي الأقل عن التساؤلات السياسية المهمة. ولكن البعض ينكر أنه يمكن لأيًاً من هذه الحجج، أواقتران البعض منها البها بالآخر ،

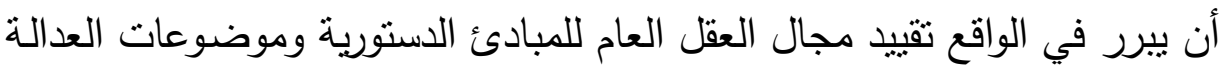
الرئيسة. (xxviii)

وتوسع وجهة نظر بديلة - مستمدة من التصـور الخاص بـالاحترام والقسر -

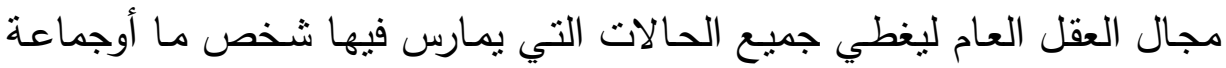

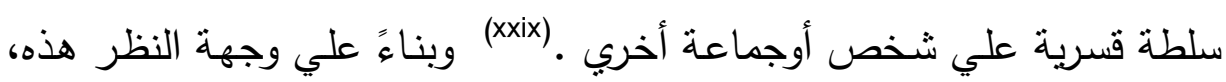

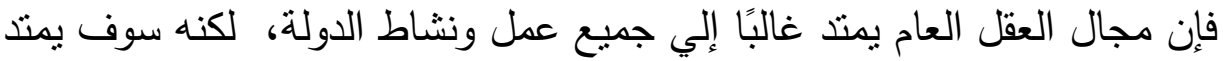
أيضًا ليشمل الاستخدام غير السياسي للاكراه خلال عناصر خاصة. وعلي ولي الرغم

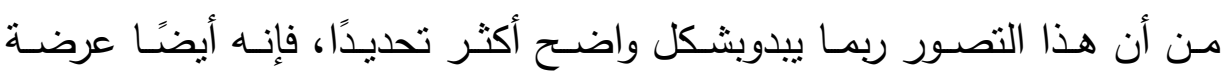
للاتهام بأنه أكثر وأقل شمولاً علي حد سواء. لبن 


\section{ثالثًا: جمهور العقل العام :}

لمن تحتاج القواعد أوالمبادئ إلي أن تكون مبررة؛ بمعني، من هم الأشخاص

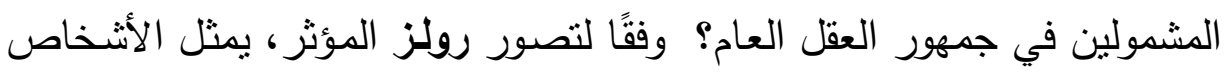

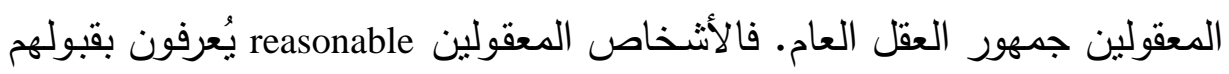
لفكرتين أساسيتين. الأولي، أنهح " مستعدون لاقتراح المبادئ والمعايير بوصفها

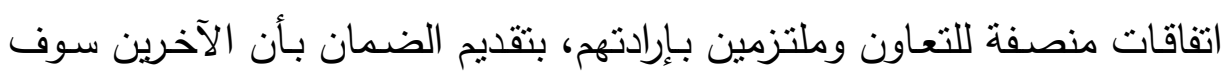

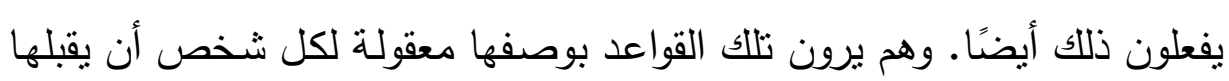

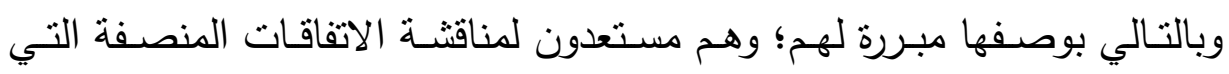

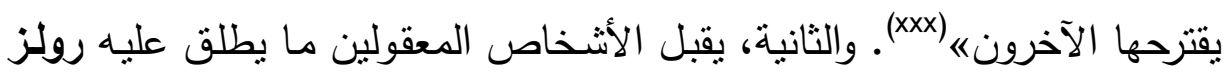

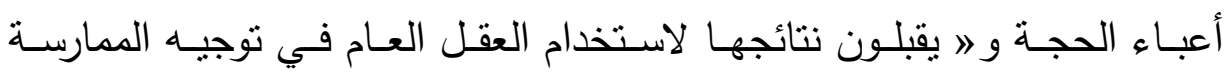

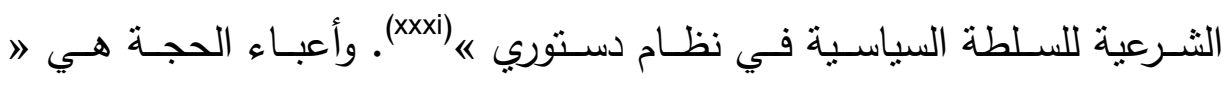

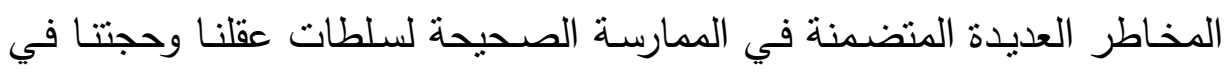

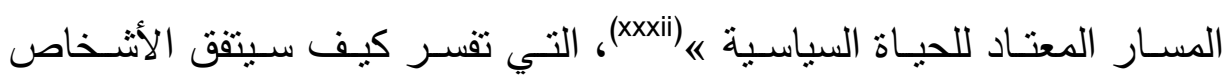
المعقولين والعقلانيين باستمرار حول موضوعات عديدة عن القيمة والأخلاق.

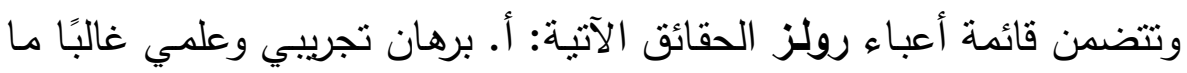

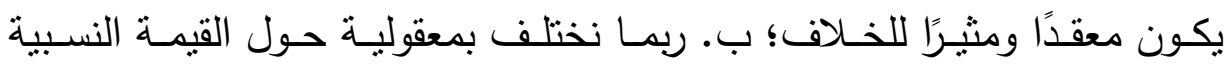

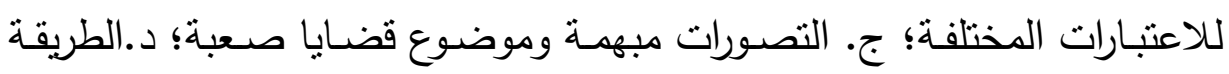

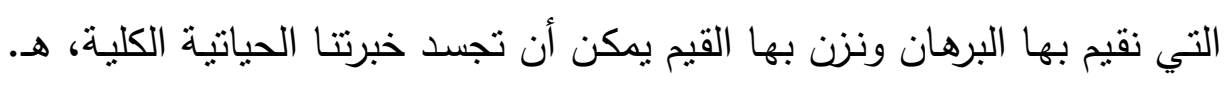

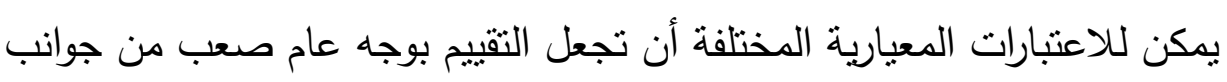

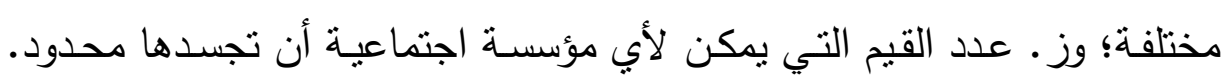

وتفسر أعباء الحجة لماذا سينقسم الأشخاص المعقولين والعقلانيين علي الدوام

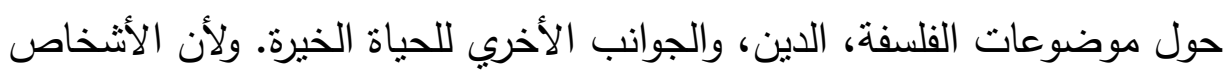

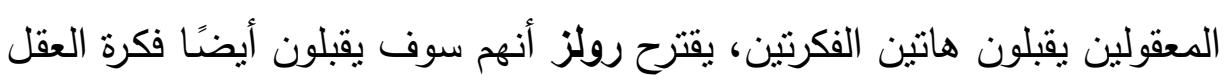


العام - الاتفاقات الوحيدة للتعاون الاجتماعي التي سوف تبدومنصفة في تحديد أعبـاء الحجـة سـوف تكـون الاتفاقـات التي يمكن تبريرهـا بـاللجوء إلـي النمـاذج

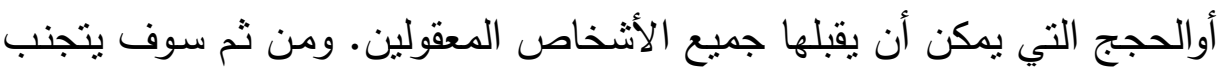

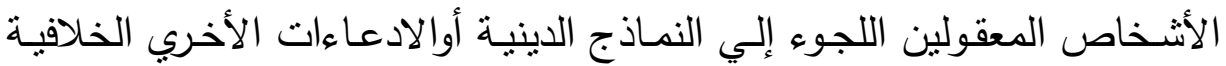

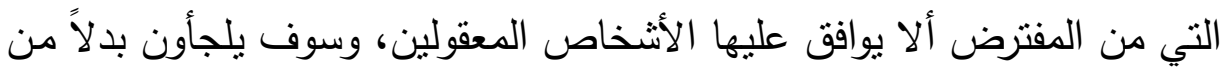

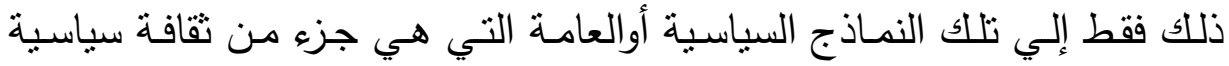

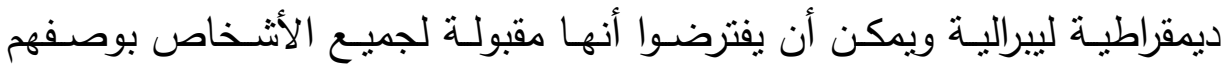
معقولين وعقلانيين. (xxiv)

وقدم جاوس وجهة نظر أقل مثالية بعض الثئ، والتي يقترح فيها أننا يجب أن نتصور أعضاء هذا الجمهور - ويطلق عليهم أعضاء العامة - بوصفهم نظراء مثاليين لأشخاص حققيين يطبقون قواعدنا السياسية والأخلاقية باعتدال. وأعضاء العامـة هؤلاء 》 ليسوا كذلك مثاليين من حيث أن تفكيرهم يتعذر بلوغه بالنسبة

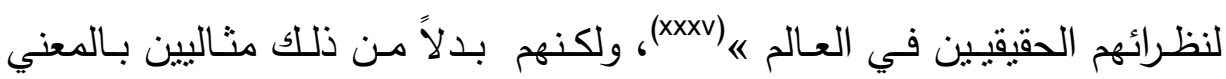
التالي: إنهم يدعمون المعتقدات التي سوف يبررها نظرائهم في العالم الحقيقي في دعمهم لها بعد مشاركتهم في " قيمة محترمة " للتفكير الحسن. (xxxvi) وهذا المستوي المعتدل للمثالية يضمن أن جمهور العقل العام سوف يكون أكثر تتوعًا إلي حد بعيد عن الجمهور الذي تصوره رولز. وسوف يشمل هذا الجمهور الأعضاء الذي يلتزمون بمعايير مختلفة للعقلانية ولايهم مجموعة متتوعة بشكل

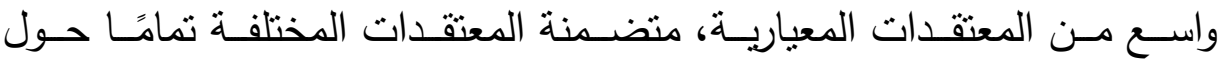
موضوعات العدالة الرئيسة.

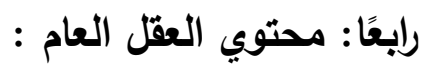

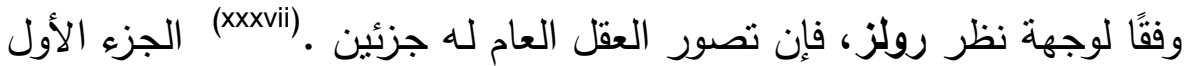

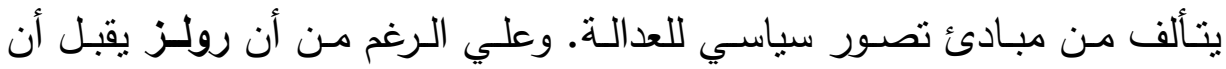

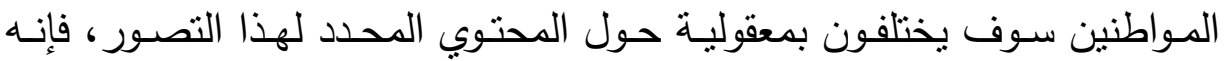


يدعي أن هذا الاختلاف سوف يكون مقيدًا " لعائلة " مـن التصسورات السياسية

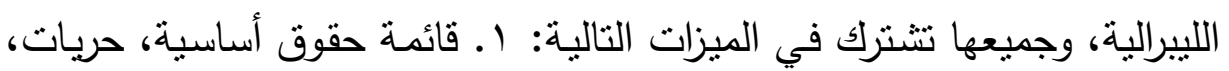

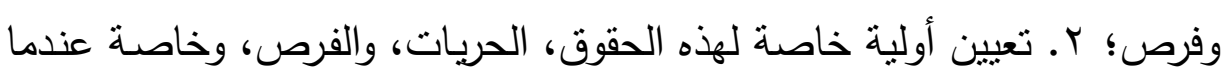

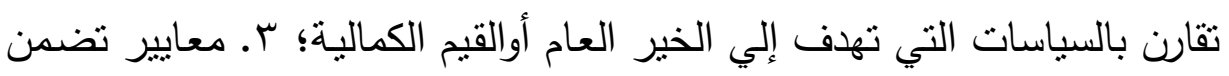

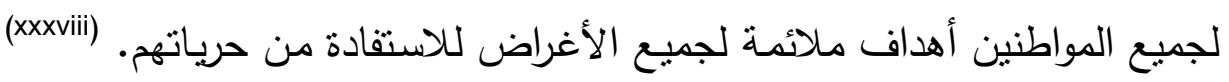

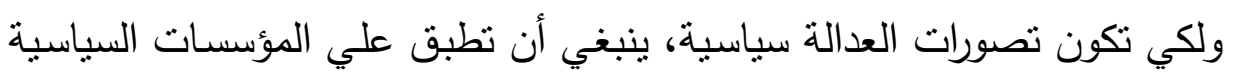

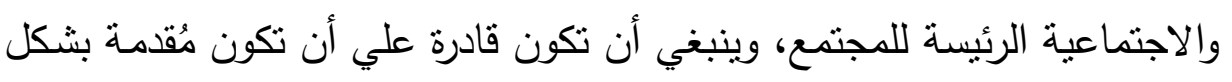

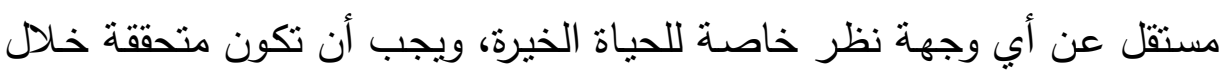
اللجوء إلي النماذج المتضمنة في الثقافة السياسية العامـة لديمقراطية دستورية.

ومن ثم، بالنسبة لــ رولز، فإن بعض الأمتلة النموذجية للقيم السياسية للعدالة

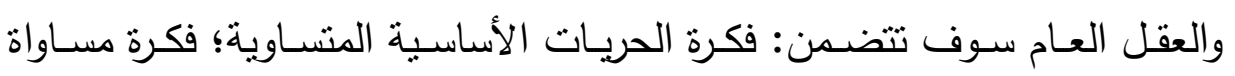

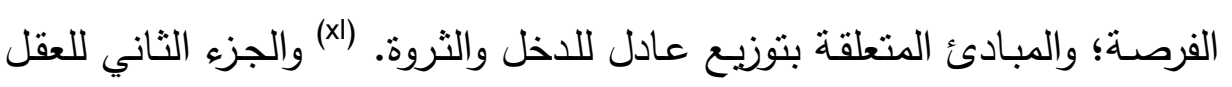

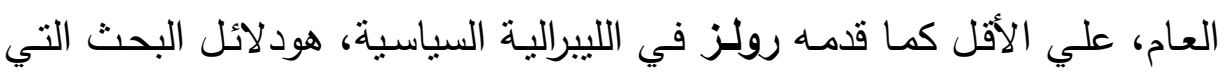
تتمل مبادئ التفكير وقواعد البرهان التي تحدد كيف تطبق المبادئ الموضوعية، فضلاً عن الفضائل المدنية المهمة منل المعقولية والكياسة. (xli)

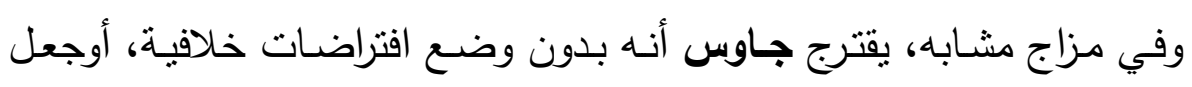

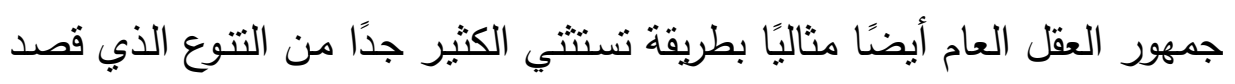

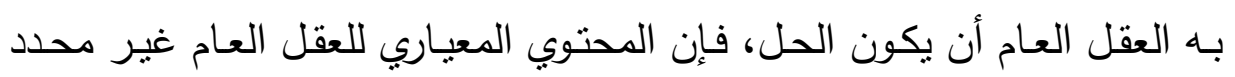

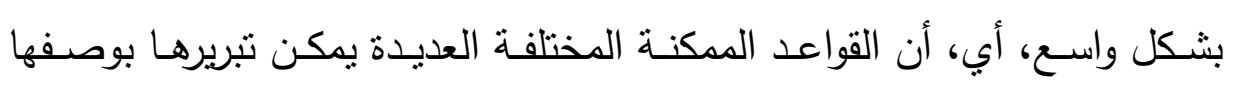

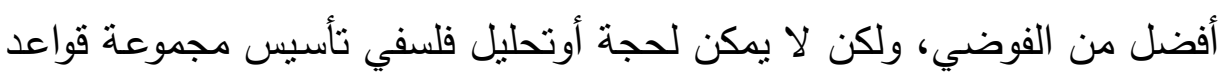

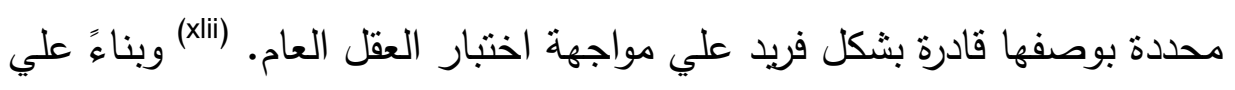

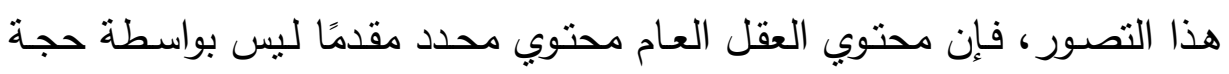

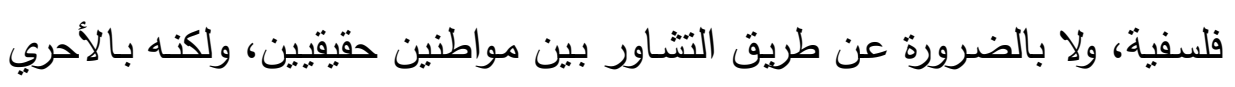


محدد بواسـطة عمليـة تقييميـة ذات مسـار مسـتقل، بواسـطتها تتطـور القواعـد المستقلة وتُختار خلال فضيلة قدرتها علي جعل الحياة التعاونية مدكنة. وعلي الرغم من أن معظم النقاش المتعلق بمحتوي العقل العام ركز علي سؤال المحتوي المعياري، فهنالك أيضنَا تسـاؤلات مهمـة حول المنظور الآخر لمحتوي العقل العام - الذي يصفه رولز بأنه دلائل البحث. وبقتزح رولز أن دلائل البحث هذه توجـه المـواطنين إلي أن يمتتعوا عن اللجوء إلـي \ مبـادئ فلسـفية أودينيـة شـاملة - عمـا نـراه كـأفراد أوكأعضـاء اتحـادات بوصـفه الحقيقـة الكاملـة - ولا لنظريات اقتصـادية مفصلة عن الموازنـة العامـة، يقول، إذا كانت هذه النظريـات محل نقاش «• وبقترح بدلاً من ذلك أن المواطنين يجب أن يعتمدوا علي 》 حقائق واضحة مقبولة علي نطاق واسع الآن، أومتاحة، للمواطنين بوجهه عام «، والتي تتضدن استتناجات العلوم عندما لا تكون مثار خلاف. (xliii) وهناك علي الأقل منظور واحد محير لهذا المقترح. وكما يعترف رولز، أحد الأشياء التي لا يتفق حولها الأشخاص المعقولين هي طبيعة الحقيقة نفسـها. فهنالك نظربات فلسفية منتافسـة عن الحقيقة، التي نكون فكرة العقل العام فيها جزء محوري، ل بدون تصور الحقيقة «(xliv). ولكن كيف يمكننا، بدون تصور الحقيقة، إعطاء معني لما يقوله رولز عن دلائل البحث، وخاصة ادعائه بأن المواطنين يجب أن يعتمدوا علي 》 الحقائق الواضحة المقبولة الآن علي نطاق واسـع «؟ ويبرهن البعض علي أن رولـز مخطئ، وأن الفلسفة السياسبية لا يمكنها علي الأقل الابتعـاد عن الادعـاءات الخلافيـة حـول طبيعـة الحقيقة. (xlv) ويقبل آخرون أن الفلسفة السياسية يجب أن تبتعد عن النظريات الفلسفية الخلافيـة عن الحقيقة، ولكنهم يصـرون علي أن العقل العـام يتطلب " تصور " سياسي " ( بوصفه معارض للتصور الفلسفي ) للحقيقة. (xlvi) 


\section{خامسًا: بنية العقل العام :}

مـن أجلـ أن يواجـه مبدأ أوقاعدة مـا مقترحـة، نطلق عليه س، اختبهار العقل

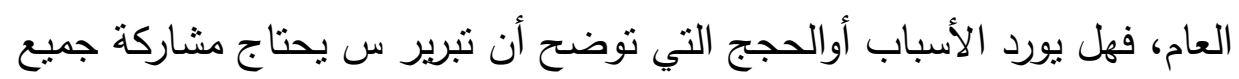

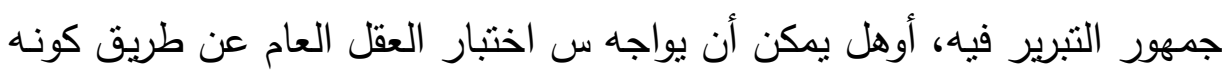

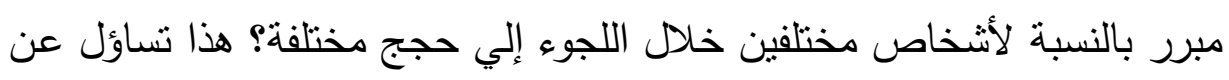

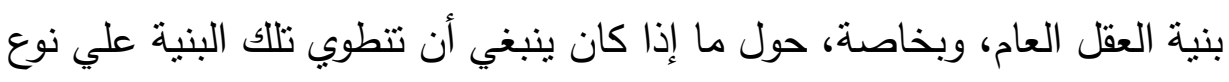

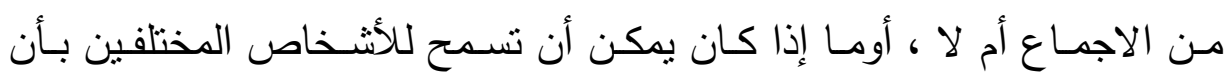
يجتمعوا علي نفس القاعدة أوالمبدأ لأسباب مختلفة نمامًا. (xlvii)

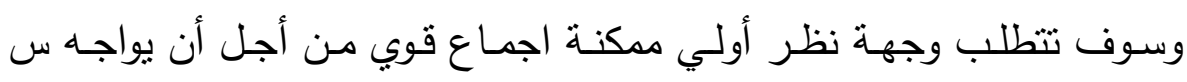

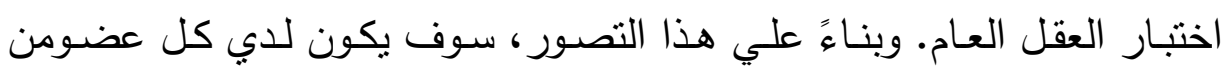

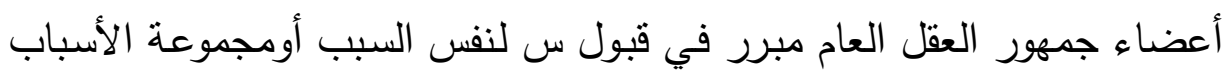

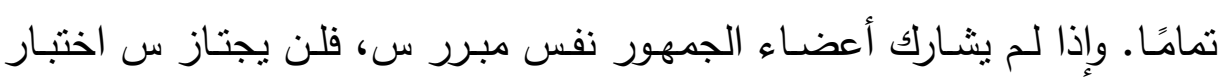

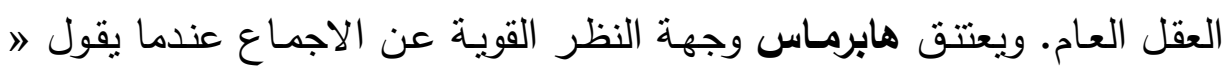
ينبغي أن يقوم الاجماع الذي بحدث خلال الحجة علي أسباب ممانلة قادرة علي الطي

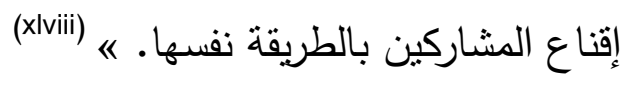
وتتطلب وجهه نظر ثانية إجماع ضعيف فقط. وبناءً علي وجهة النظر هذه، إنها

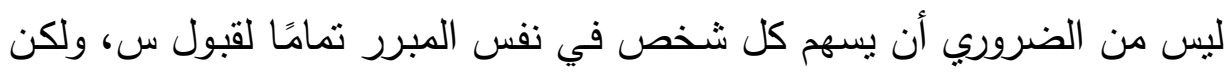

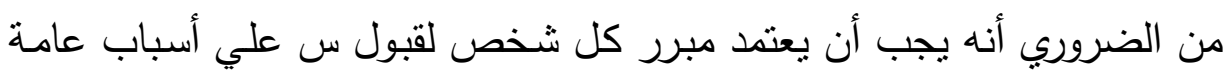
أومشتركة فقط، أب، الأسباب التي سوف يقبلها جميع أعضاء الجمهور التبريري

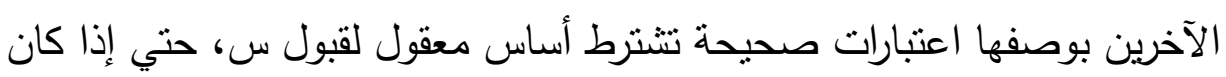

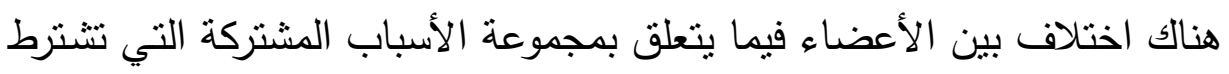

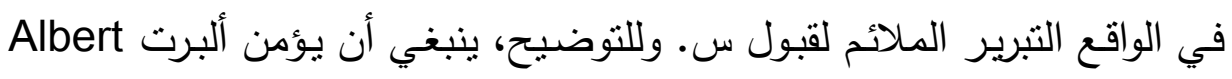

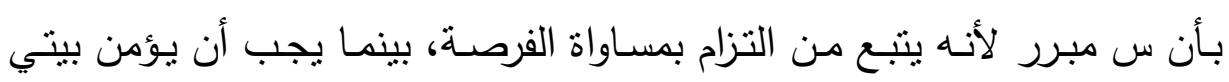
بetty 
ولكن بشرط أن يكون كلا هذين الاعتبارين - مسـاواة الفرصـة والحق في حريـة الدين - مقبولاً بوصفه اعتبارات معيارية صحيحة خلال جميع أعضاء الجمهور

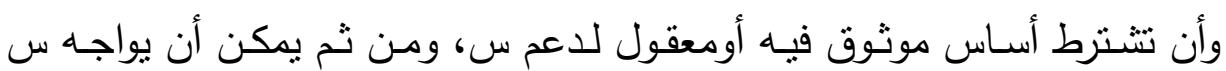

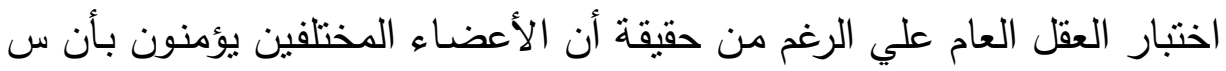

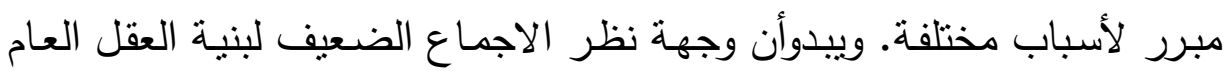

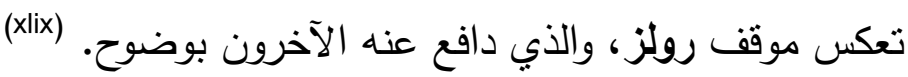

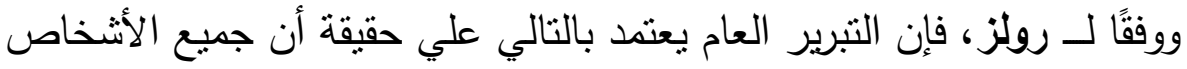

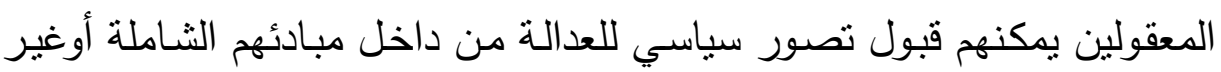
العامـة، ولكن العقل العام نفسه لم يشر إلي محتوي تلك المبادئ غير العامـة -

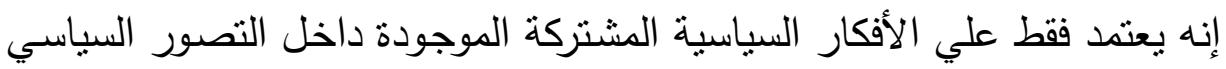
للعدالة .

ويبدوأن وجهة نظر الالتقاء تعتمد علي افتراض أن التبريرات والأسباب يمكن

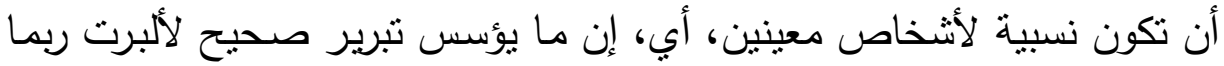

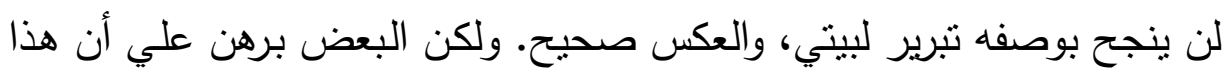

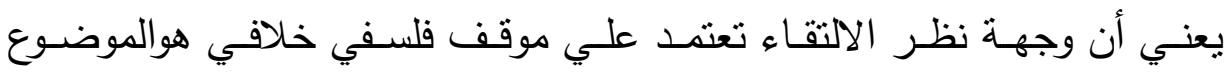

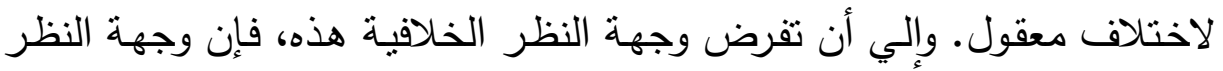

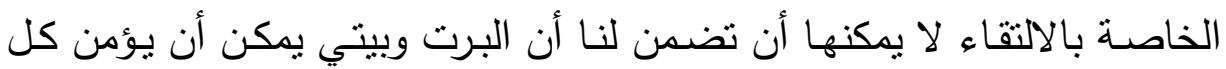
منهم بإخلاص أن الآخر مبرر في قبول س. ومن ثم فإن وجهة النظر الخاصـة

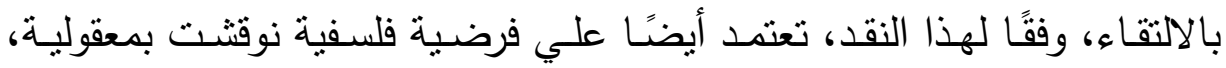
أوبطريقة أخري أخفقت في بيان أن جميع المشاركين في تبرير التقائي مبررين

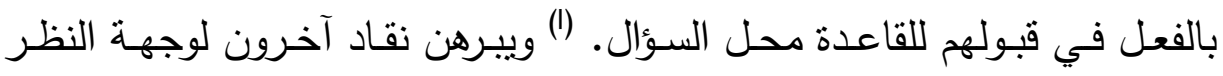

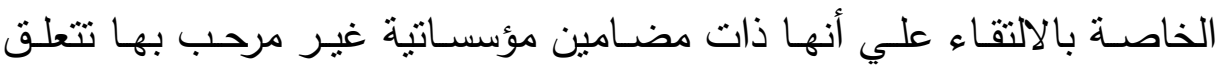

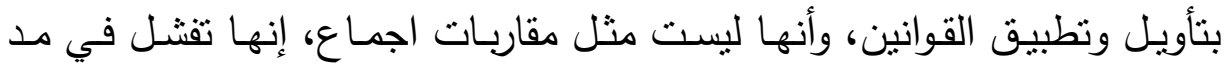


المواطنين بنموذج ضمان متبادل يتعهد فيه الآخرون بمشروع التفكير العام حول

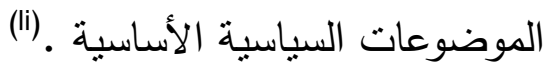

وبالنسبة لهذا الجزء، فإن أنصار وجهة النظر الخاصة بالاهيه : الالتقاء يبرهنون علي

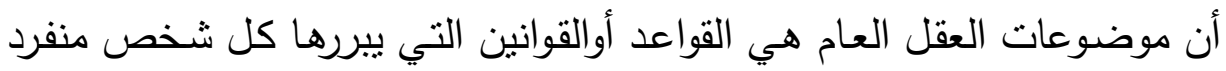

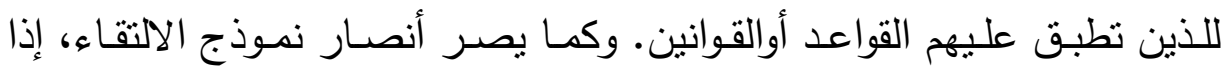
تمكن الأثـخاص المختلفين مـن تبرير قبول نفس القاعدة لأشخاص مختلفين

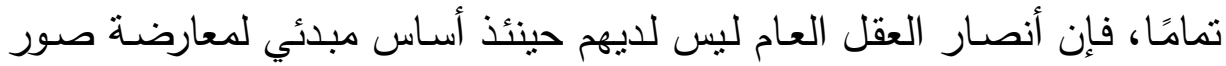

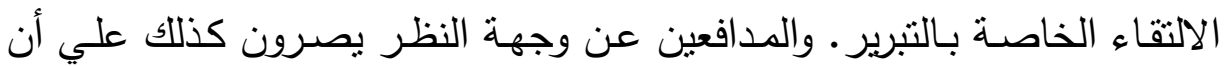
مطلب الاجماع أوالأسباب المشتركة مطلوب بشكل مفرط، ويخفقون في التوافق

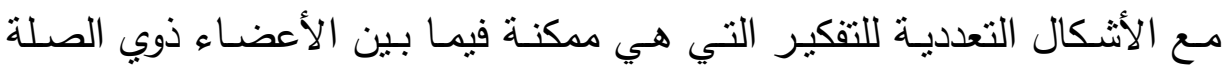

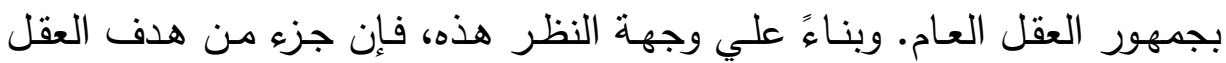

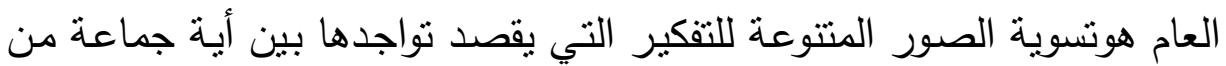
المعقولين متتافسة بمعقولية.

\section{سادسًا: موقع وواجبات العقل العام :}

ما هي الواجبات التي تفرضها فكرة العقل العام علي الأفراد؟ وفي أي الميادين أوالجوانب من حياتتا تطبق مطالب العقل العام؟ لونيات

ييرهن رولز علي أن العقل العام يفرض واجب كياسة duty of civility أخلاقي

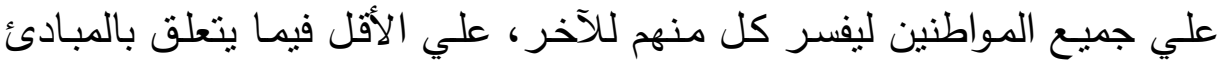
الدستورية وموضوعات العدالة الرئيسة، كيف يمكن دعم المواقف السياسية ه التي

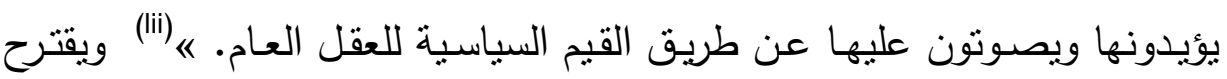

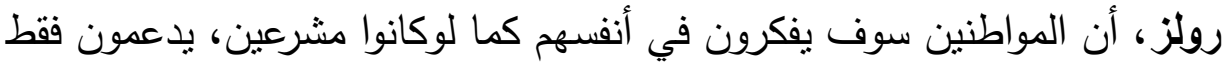
تلاك المواقف السياسية التي يؤمنون بأنها سوف تكون مبررة باللجوء إلي الأسباب التي سوف يقبلها جميع الأثخاص المعقولين، ويدعمون الموظفين الحكوميين بهذا المعيار . (iii) ولكن يبدوأن رولز يؤمن بأن العقل العام يفرض واجبات أعظم 
علي الموظفين العموميين: الموظفين المنتخبين وأولئك الذين يرشحون للوظيفة، وطاقمهم، والقضـاة. وذلك لأن الأشخاص، في هذه الأدوار ، يعملون فيما يعتقد

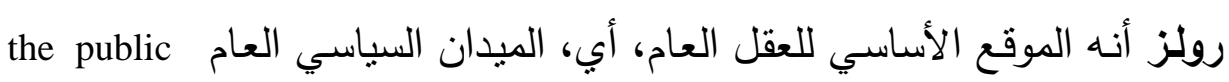
-political forum

وهكذا فإن التصـورات المختلفة للعقل العام تخضـع إلي وجهات نظر مختلفة بشكل حاد تتعلق بواجبات المواطنين والموظفين العمومبين. ووفقًا لوجهة نظر رولـز ، ووجهـات النظـر الأخـري المشــابهة لهـا، ينبخـي أن يمتــع المـواطنين

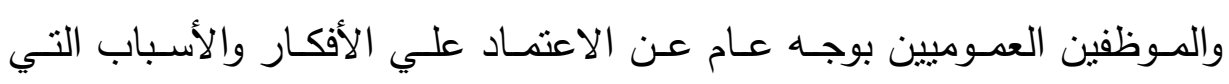
يرفضها المواطنين المعقولين الآخرين، ويجب أن يبينوا دائمًا كيف يمكن أن تكون المواقف السياسية التي بدعمونها مبررة بـاللجوء إلي القيم السياسية المشـتركة. وبناءً علي التصورات الأخري، ربما تنظم فكرة العقل العام الطربقة التي نصمم بها مؤسساتتا الديمقراطية، وربما تكون معيار يمكن أن تقرضـه المبادئ الخاصـة

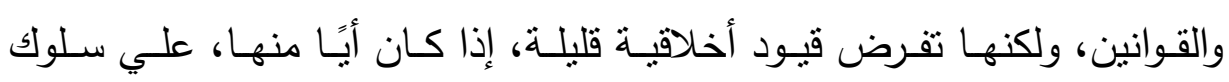
المواطنين وربما حتي علي الموظفين العمومبين. سابعًا: الاعتراضات علي فكرة العقل العام : تناول هذه النقطة بعض الاعتراضات الأكثر بروزًا علي فكرة العقل العام. وهذه الاعتراضات ليست حصرية، وبعضها ينطبق علي بعض تصورات العقل العام،

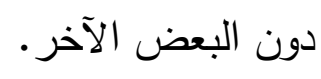
أ. الاحباط الذاتي الاحصن

توضـح لنـا فكرة العقل العـام أن - بالنسـبة لمجموعـة مـن القواعـ السياسـية أوالأخلاقيـة - القواعـد التي نحـن بصـددها ليسـت شـرعية أوتفتـر إلـي سـلطة معياريـة، حتـي يمكـن أن تكـون القواعـد التي نحـن بصـددها مبـررة، أومقبولـة بمعقولية، لجميع أولئك الذين تطبق عليهم القواعد. وبيرهن بعض النقاد علي أن فكرة العقل العام محبطة ذاتيًا لأن الفكرة نفسها لا يمكن أن تكون مبررة لجميع 
أولئك الأثخاص الذين يطبقون الفكرة. (iv) ويشير الناقد إلي أن العقل العام

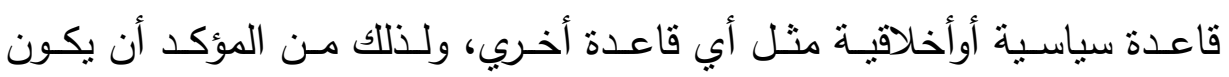

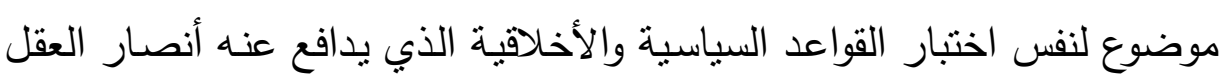
العام. ولكن فكرة العقل العام لن تكون قادرة علي اجتياز هذا الاختبار . وبشكل واسع، هناك طريقتين للدفاع عن فكرة العقل العام ضد هذا الاعتراض.

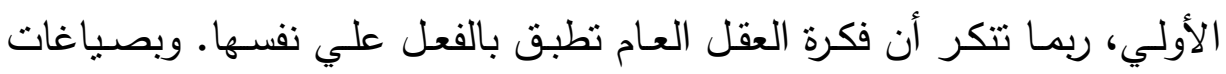

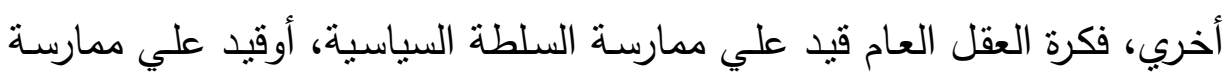
القسر ، ولكن هي نفسـها ليست ممارسـة للسـلطة السياسية، ولا ممارسـة للقسـر . وعندما يعلن أنصار العقل العام أن القواعد الأخلاقية أوالسياسية يجب أنسان أن تكون

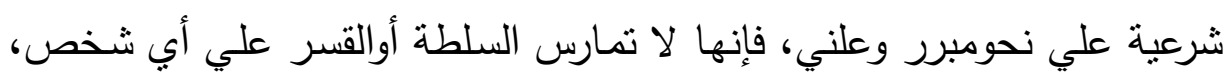

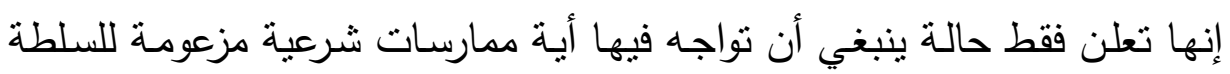
أوالقسر لتكون شرعية. وعلي الرغم من ذللك، ربما يعتمد نجاح هذا الرد علي افتراض خلافي لصالح

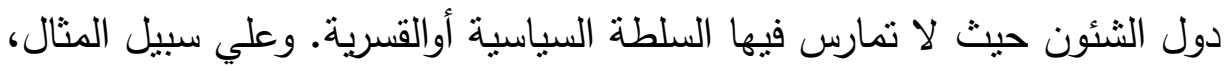

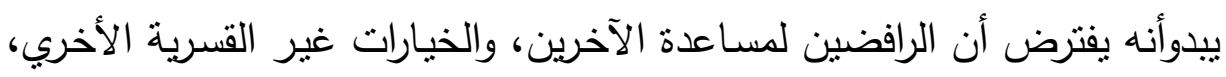

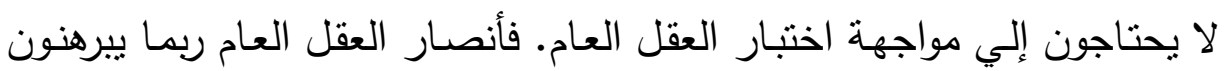

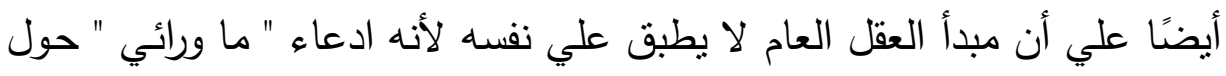

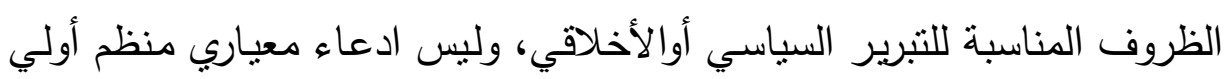

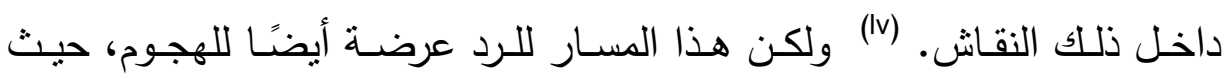

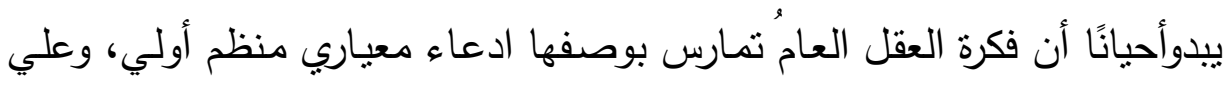

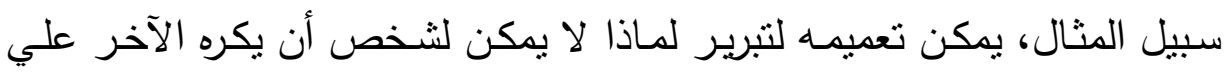

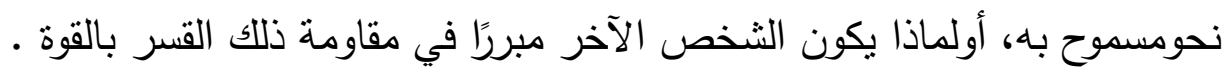
والطريقة الثانية للدفاع عن العقل العام من الاعتراض هي القبول بأن الفكرة

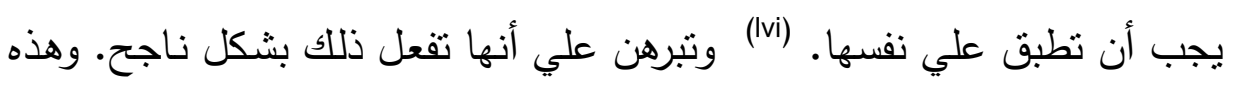


الاستراتيجية يمكن النضال فيها بطرق عدة. وربما يشير أنصار العقل العام إلي

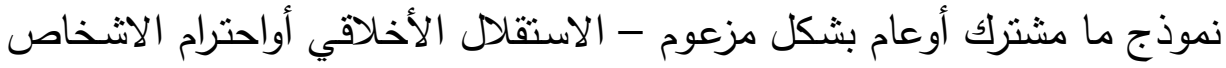
- ويبرهنون علي أن هذا النموذج علي حد سواء يبرر النزام بعقل عام وهومبرر

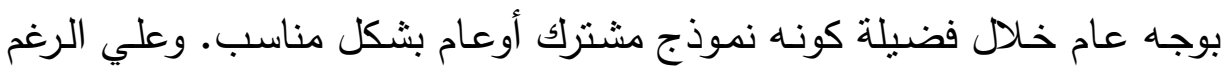

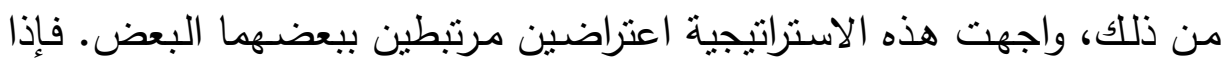
كان النموذج محل النقاش مصاغ بطريقة مفصلة أوثرية بشكل كاف، فإن تعهد كهذا بعقل عام استتبع بشكل معقول النموذج، وبالتالي ينطوي النموذج علي لهي الحقيقة

أوصت تصورات عديدة للعقل العام، ولاسيما تصور رولز إلي حد بعيد، بأننا نحدد القواعد السياسية والأخلاقيـة بينما نمتتع، بطرق عديدة، عن عن الادعاءات

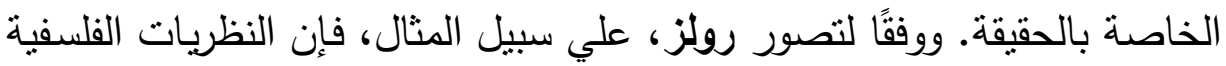
للحقيقة هي نوع من الثئ الذي يُفترض أن الأشخاص المعقولين لا يتفقون حوله،

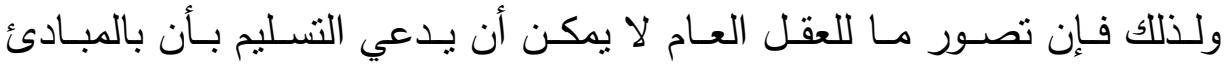

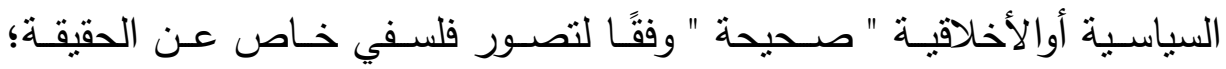
وبـالأحري يمكنه أن يسلم فقط بـأن المبادئ " معقولـة ". (Ivi) وتصـورات عديدة

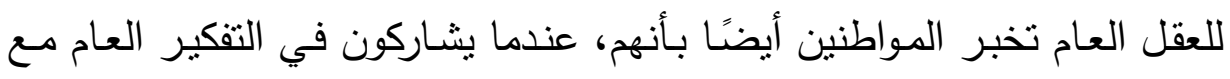

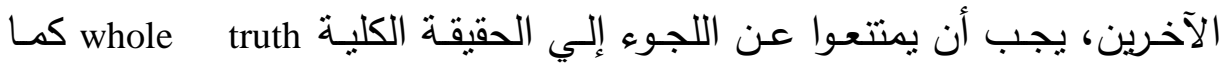

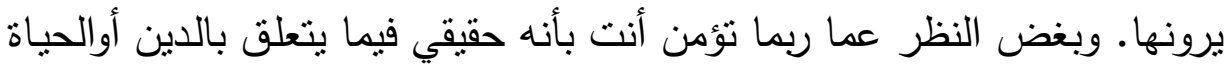
الخيرة، فإن المواطنين يجب أن يمتتعوا عن اللجوء إلي هذه الحقائق، وأن يلجأوا

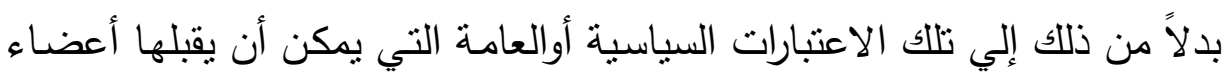
الجماعة السياسية أوالأخلاقية المعقولين الآخرين.

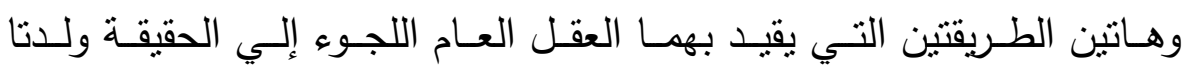

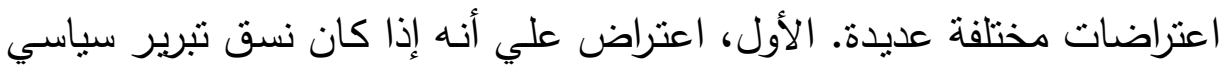

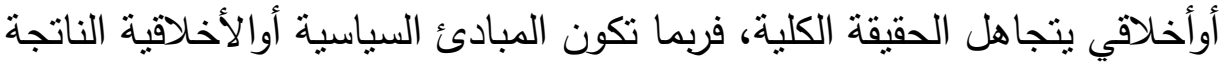


خاطئة. فعلي سبيل المثال، إذا كان من الحقيقي أن جميع الخطاة سوف يذهبون

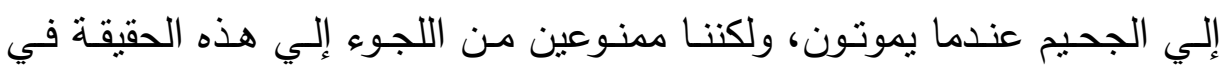

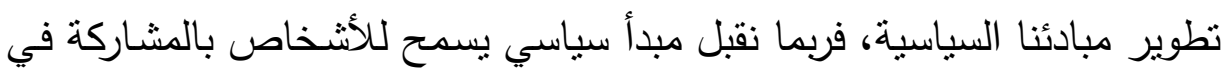
نشاطات آثمة عديدة. وعلي الرغم من ذلك، إذا أمكننا اللجوء إلي الحقيقة الكلية عن الجحيم، فسوف نري أن هذا المبدأ السياسي خاطئ. والإعتراض الثاني، ينبغي أن نقلق من أنه إذا كان تصور ما للتبني التبرير السياسي

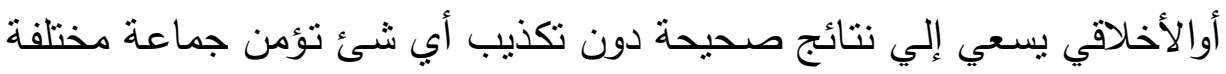
من الأشخاص أنه حقيقي -علي سبيل المثال، دون تكذيب وجهات النظر الدينية المعقولة لأي شخص - فإن تصور كهذا سوف » بلتزم بوجهة النظر التي مفادها أنه من غير المرغوب فيه إنشاعة معتقدات خاطئة أواستتناجات غير سليمة.هـ(Iviii) أما الاعتراض الثالث، فيركز بعض النقاد علي أن ادعاء رولز بـأن محتوي

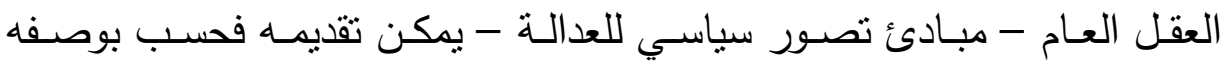
معقول، لكن ليس بوصفه صحيح. وإذا كانت تلك المبادئ معقولة فحسب، لكنها

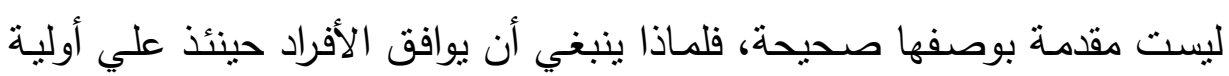
هذه المبادئ في قراراتهم حول كيف يتصرفون، وخاصة عندما ينال هذه المبادئ

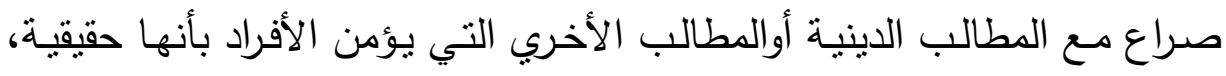
وليست معقولة فحسب؟.

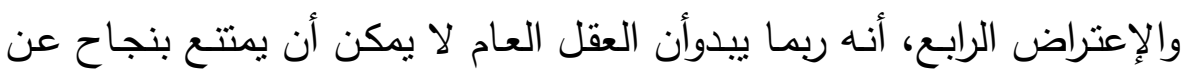

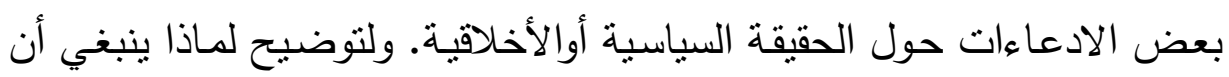

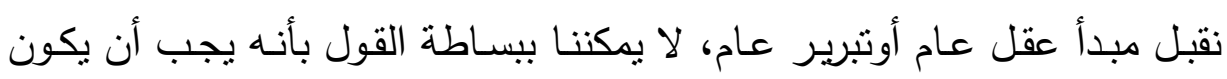

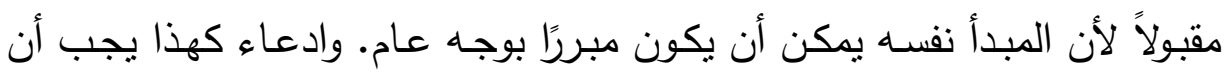

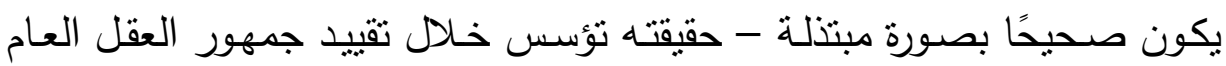
لأولئك الذين يقبلون فكرة العقل العام - ولكن هذا لا يبرر المبدأ، ولا يميز مبدأ

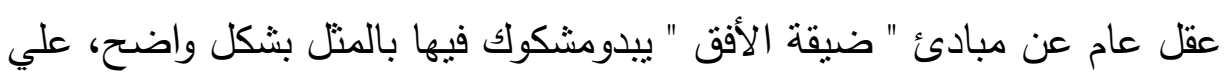


سبيل المثال، مبدأ نسليم بأن المبادئ الأخلاقية صحيحة فقط عندما يقبلها ألبرت،

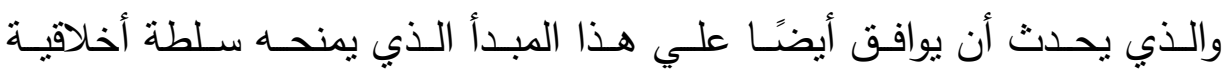

اسنثنائية. (اسن)

والخامس، اقترح نقاد آخرون أن فكرة العقل العام تستتبع أن الأفراد يجب أن

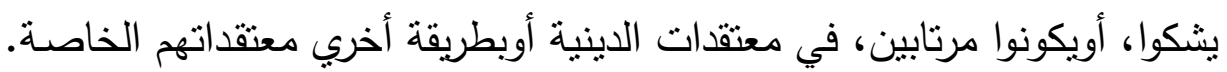

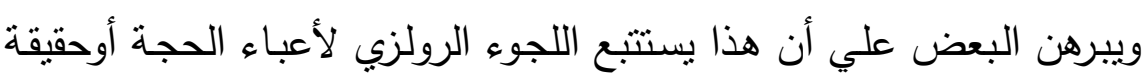

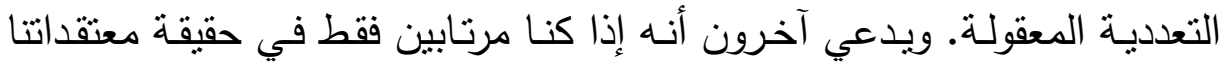
الخاصة فسوف يكون من المنطقي أن نحصر تلك المعتقدات عندما نتشاروحول

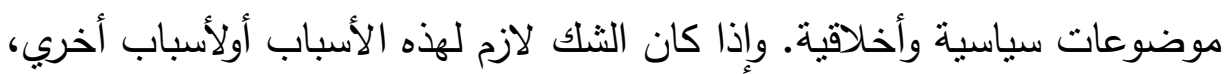

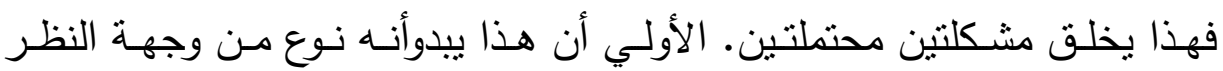

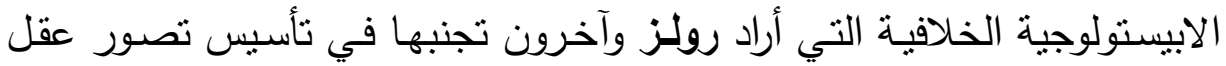
عام. والأخري أن أنخاص مدفوعين جيدًا ومعقولين بشكل واضـح ليسوا مرتابين في معتقداتهم الدينية أوالخاصة، ولكن هل يعني هذا أن هؤلاء الأشخاص بمكنه حينئذ قبول فكرة العقل العام؟ معاج قدم أنصار العقل العام ردود عديدة علي الاعتراضـات السابقة. أولها، وأكثرها

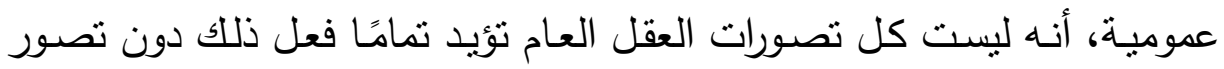
الحقيقة، بالطريقة التي يهذف تصور رولز الخاص فعل ذلك من خلالها. والثاني،

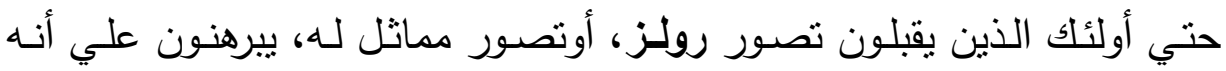
يمكن أن يواجه الاعتراضات الموجهة ضده. ووفقًا للبعض، هـذا لأنـهـ مـن الخطـأ تأييـد أن نظريـة العقل العـام أوالتبريـر

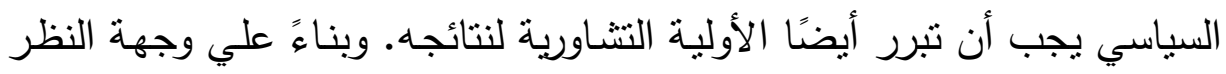

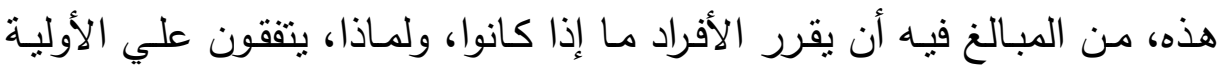

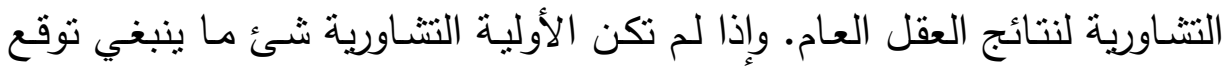
تأييد نظرية عقل عام له، فإن الإعتراض الثالث، والرابع، والخامس أعلاه يمكن 
نزع فتيلهما. (xii) والثالث، يشير أنصار العقل العام إلي أنه عندما تتطلب مناهج

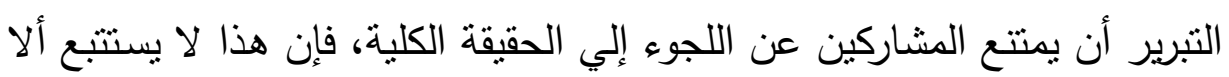

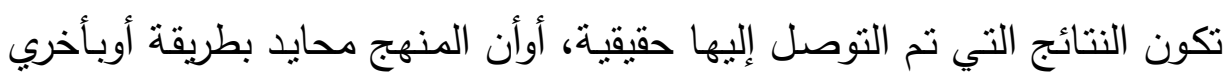
فيما يتعلق بحقيقة النتائج التي تم التوصل إليها. (xiii)

ج. النقصان

أحد أكثر الاعتراضـات أهمية التي وجهت ضد فكرة العقل العام تتعلق بقدرته علي تقديم الحلول لجميع، أوغالبًا جميع، التسـاؤلات السياسية والأخلاقية المهرية

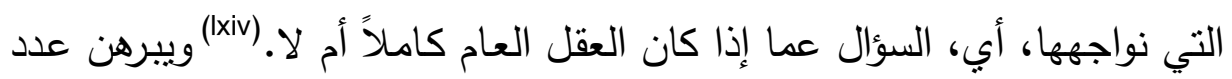

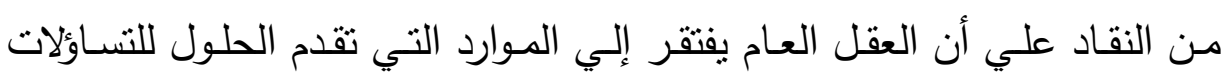

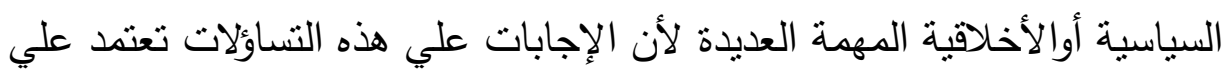

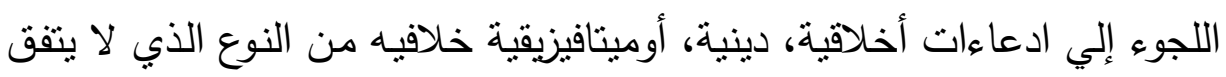

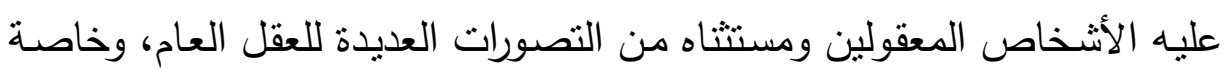
تللك التصورات التي تقر مقاربة إجماع لبنية العقل العام. (Ixv)

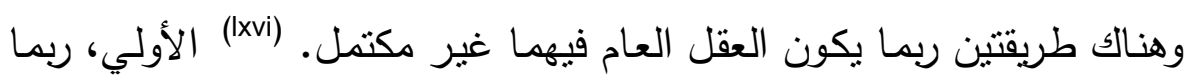

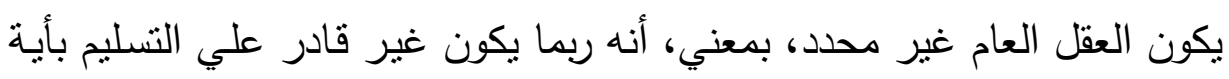

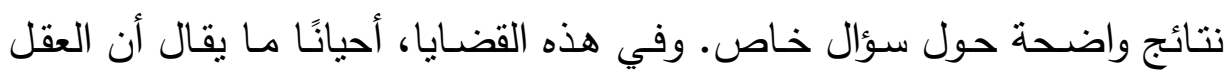
العام " نفذ ": فمحتواه يبرهن ببساطة علي عدم كفاية التسليم بإجابة علي السؤال

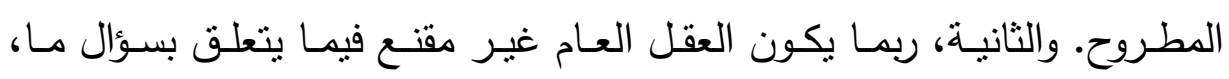

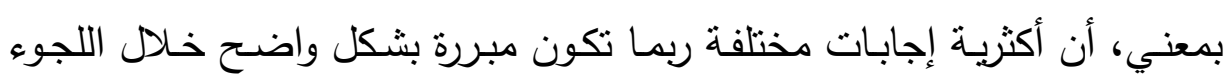

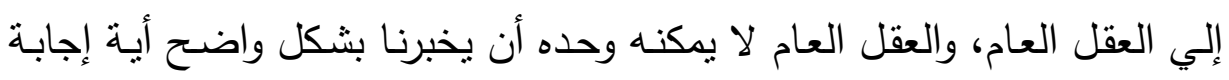

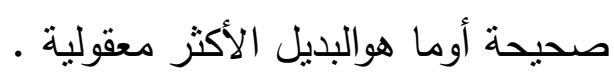

وعدم التحديد هوالاتهام الأكثر جدية، ولكن النقاد ييقون علي أنه حتي إذا كان النان

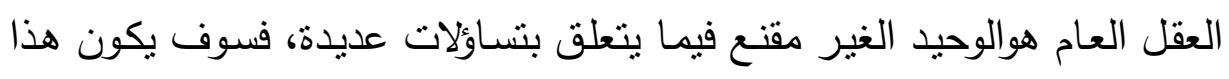

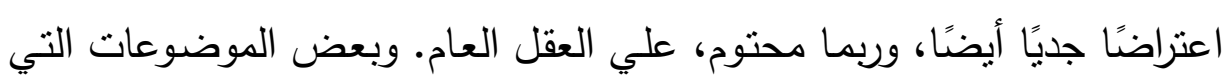


تتعلـق بـزعم النقـاد بـأن العقل العـام أيضًا غيـر مقتـع وغيـر محدد يتضــن:

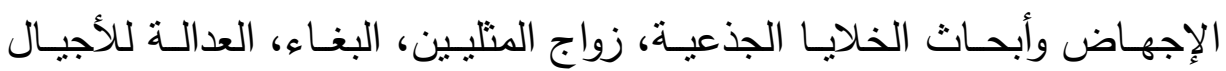
المستقبلية، ومعاملة الحيوانات، وقضايا أخري حيث يزعم النقاد أن تقديم الإجابة

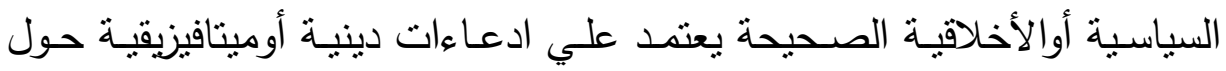

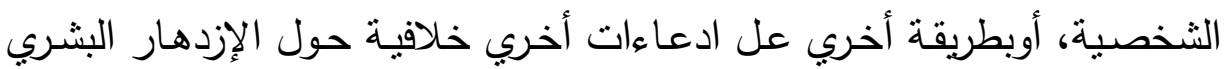

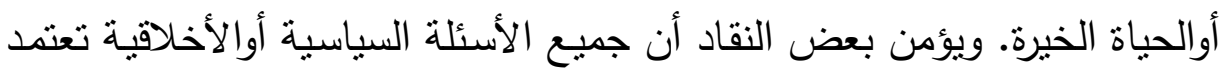

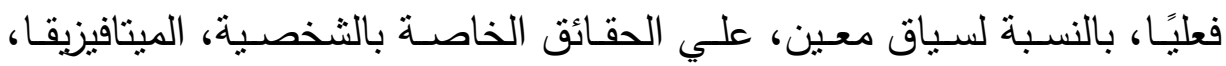

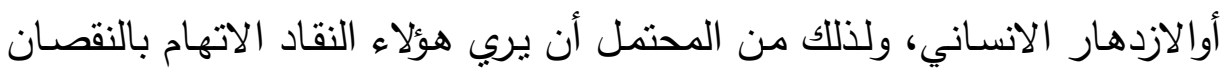
بوصفه مشكلة منتشرة وعميقة للعقل العام . د. الاستثناء

يبرهن بعض النقاد علي أن فكرة العقل العام - وخاصة تصور رولز لها هي فكرة غير منصفة بطريقة ما أواقصائية بإفراط. وهذا الاتهام غالبًا ما يوجها باسم هؤلاء الذين سوف يعتمدون علي الحجج الدينية عندما يتشاورون حول أسئلة

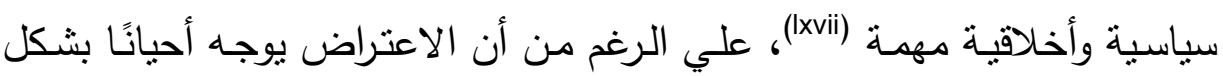

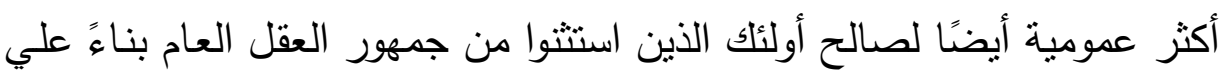

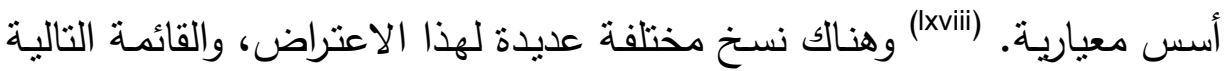
ليست شاملة. ولكن علي نحوأكثر قوة، العقل العام زائف: إنه يدعي أنه منهج محايد أوغير متحيز للتبرير السياسي أوالأخلاقي، ولكن هذا، في الواقع، صورة

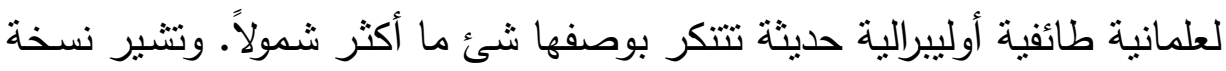
ثانية، أقل حدة، لهذا الاعتراض إلي أنه حتي نظريات العقل العام تلك التي ليست علمانيـة بشكل واضـح سـوف تجعل من الصـعب إلي حد كبير ، علي التوازي،

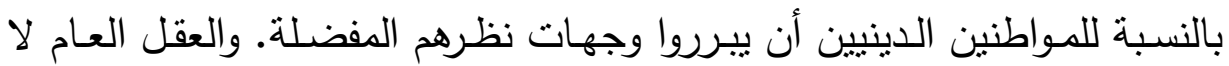

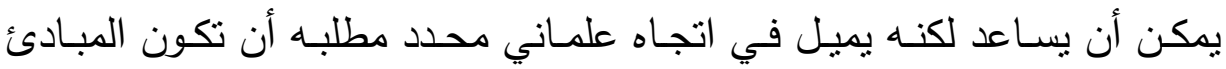
أوالقواعد مبررة بمعقولية لجميع أعضاء الجماعة. 


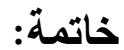

يتسائل العقل العام عن ماهية الحقوق التي ينبفي أن تفرضها الدولة، وأن تضمن

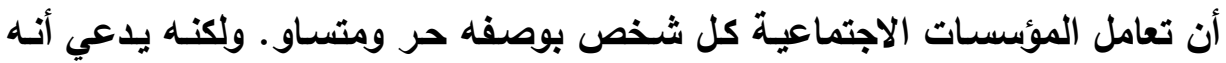

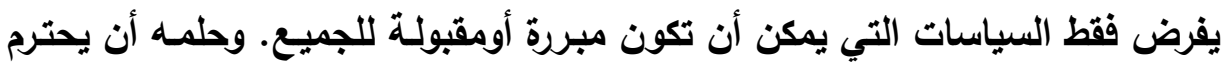

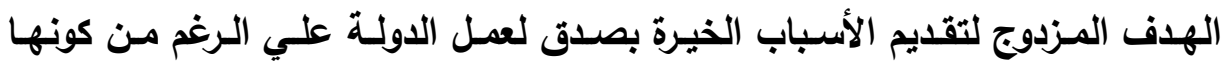
مقبولة بوجه عام. وينتقل العقل العام من ناحية أنه ينبغي أن يتجنب الطلم المستحيل

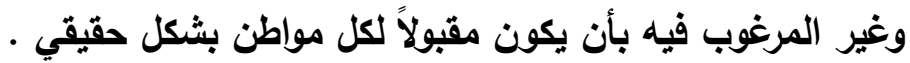

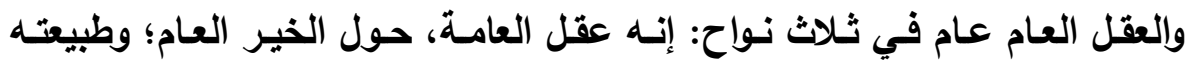

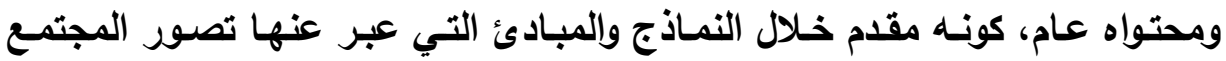

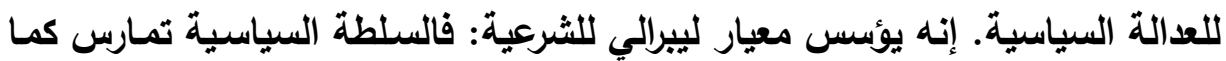

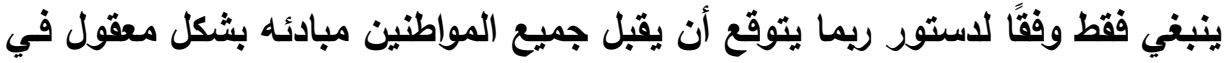
ضوء مبادئ ومثل مقبولة بالنسبة لهم بوصفها معقولة وعقلانية .

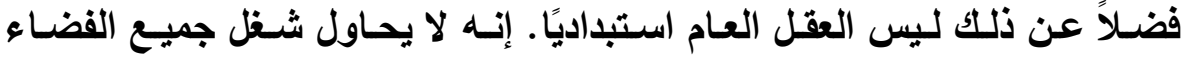

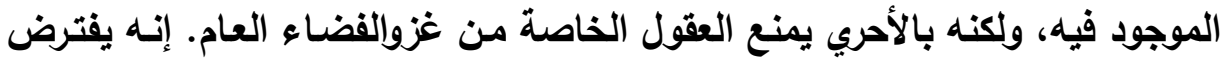
أن العقول الخاصة ريما تعترف بـه بوصفه مجال الحقيقة الكلية، ومصدر التساؤلات

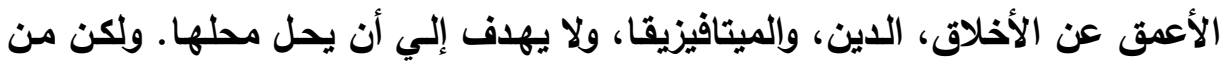

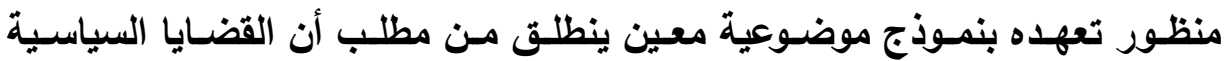

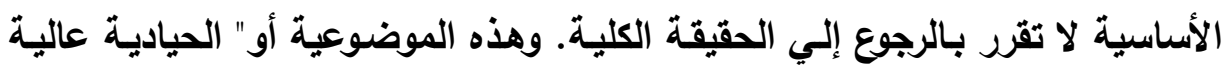
التنظيم "، كما يطلق عليها ناجل، تعلوعلي وجهة نظر عامة تميز بين ما يبرر معتقد

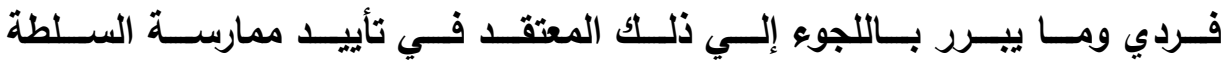
السياسية.واللييراليين مثل رولز يؤكلن علي أهية الاستقرار يرون العقل العام بوصفه شـرط مسبق لمملكـة أهداف، ويوصفه دليل علـي القبـول العـام للمبـادئ اللييراليـة

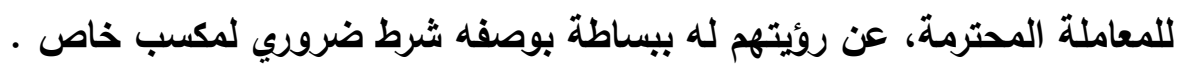




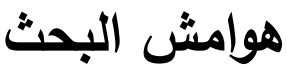

(1) Otsuka, M.; Libertarianism Without Inequality, Oxford University Press, Oxford, U. S. A, 2003, pp. 89-113.

(3) Rawls, J.; Political Liberalism, Columbia University Press, New York, U.S.A, 1996, pp. $36-37$.

: أيضًاIbid., pp 55 - 57.

(4) Galston, W.; Liberal Pluralism: The Implications of Value Pluralism for Political Theory and Practice, Cambridge University Press, Cambridge, U.S.A, 2002, pp. $46-47$.

Gaus, G.; Justificatory Liberalism: An Essay on Epistemology and Political Theory, Oxford University Press, Oxford, U.S.A, 1996, pp.131 - 136.

Wenar, L.; "Political Liberalism: An Internal Critique", pp. 32-62, Ethics, Vol. 106, No. 1, 1995, pp. 41- 48.

(5) Habermas, J.; Moral Consciousness and Communicative Action, C.

Lenhardt and S. W. Nicholsen (trans.), MA: MIT Press, Cambridge, 1990.

Habermas, J.; Between Facts and Norms: Contributions to a Discourse Theory of Law and Democracy, W. Rehg (trans.), MA: MIT Press, Cambridge, U.S.A, 1996.

(6) Habermas, J.; The Inclusion of the Other: Studies in Political Theory, C. Cronin and HP. DeGreiff (eds.), MA: MIT Press, Cambridge, U.S.A, 1998, p. 42.

(7) Bohman, J.; Public Deliberation: Pluralism, Complexity, and Democracy, MA: MIT Press, Cambridge, U.S.A, 1996.

Dryzek, J.; Discursive Democracy: Politics, Policy, and Political Science, Cambridge University Press, Cambridge, U.S.A, 1990. 
; Deliberative Democracy and Beyond: Liberals, Critics, Contestations, Oxford University Press, Oxford, U.S.A, 2000

(8) Rawls, J.; Political Liberalism, Op.cit, p. 13.

(9) Ibid., pp. 376 - 381.

(10) Gaus, G.; The Order of Public Reason: A Theory of Freedom and Morality in a Diverse and Bounded World, Cambridge University Press, Cambridge, U.S.A, 2011.

(11) Ibid., p. 184.

(12) Ibid., pp. $205-232$.

(13) Ibid.

Rawls, J.; Political Liberalism, Op.cit, p. 219. انظر أيضًا :

(14) Weithman, P.; Religion and the Obligations of Citizenship, Cambridge University Press, Cambridge, U.S.A, 2002, 188 - 191.

Quong, J.; "On The Idea of Public Reason", in The Blackwell Companion to Rawls, J. Mandle and D.Reidy (eds.), Wiley Blackwell, Oxford, U.S.A, 2013.

(15) Larmore, C.; "The Moral Basis of Political Liberalism", pp. 599-625, The Journal of Philosophy, Vol. 96, No. 12, 1999, p. 608.

(16) Ibid., p. 607.

انظر أيضًا :

Larmore, C.; "Public Reason", pp. 368-393, in The Cambridge Companion to Rawls, S. Freeman (ed.), Cambridge University Press, Cambridge, U.S.A, 2002.

Nagel, T.; "Moral Conflict and Political Legitimacy", pp. 215- 240, Philosophy \& Public Affairs, Vol.16, No. 3, 1987.

(17) Gaus, G.; The Order of Public Reason: A Theory of Freedom and Morality in a Diverse and Bounded World, Op.cit, pp. 341 - 46.

(18) Bird, C.; An Introduction to Political Philosophy, Cambridge University Press, Cambridge, U. S. A, 2006.

Quong, J.; "On The Idea of Public Reason", Op.cit. 
(19) Lister, A.; "Public Justification and the Limits of State Action", pp. 151-175, Politics, Philosophy \& Economics, Vol. 9, No. 2, 2010.

(20) Rawls, J.; Political Liberalism, Op.cit, pp. 49 - 50.

(21) Ibid., p. Ii.

(22) Ibid., p. 213.

و أيضًا :

Rawls, J.; Collected Papers, S. Freeman (ed.), MA: Harvard University Press, Cambridge, U. S.A, 1999b, p. 573.

(23) Rawls, J.; Political Liberalism, Op.cit, p. 547.

(28) Rawls, J.; Justice as Fairness: A Restatement, MA: Harvard University Press, Cambridge, U. S. A, 2001, p. 91.

(29) Rawls, J.; Political Liberalism, Op.cit, p. 235.

(30) Ibid., p. 227.

(31) Ibid., pp. $228-229$.

(32) Greenawalt, K.; "On Public Reason", pp. 669-89, Chicago Kent Law Review, Vol. 69, No. 3, 1994, pp. 685 - 86.

(33) Quong, J.; Liberalism without Perfection, Oxford University Press, Oxford, U. S. A, 2011, pp. $273-289$.

(34) Larmore, C.; The Morals of Modernity, Cambridge University Press, Cambridge, U. S. A, 1996, p. 137.

Larmore, C.; "The Moral Basis of Political Liberalism", Op.cit, pp. 607 608.

Nagel, T.; Equality and Partiality, Oxford University Press, New York, U. S. A, 1991, p. 159.

(36) Rawls, J.; Political Liberalism, Op.cit, p. 49.

(37) Ibid., p. 54.

(38) Ibid., pp. $55-56$.

(39) Ibid., pp. $56-57$.

(40) Ibid., p. 217. 
(41) Gaus, G.; The Order of Public Reason: A Theory of Freedom and Morality in a Diverse and Bounded World, Op.cit, p. 276.

(42) Ibid., p. 250.

(43) Rawls, J.; Political Liberalism, Op.cit, p. 224.

(44) Ibid., p. 223.

Rawls, J.; Collected Papers, Op.cit, pp. 581 - 582.

(45) Rawls, J.; Collected Papers, Op.cit, p. 584.

(46) Ibid., p. 584.

(47) Rawls, J.; Political Liberalism, Op.cit, p. 224.

(51) Gaus, G.; The Order of Public Reason: A Theory of Freedom and Morality in a Diverse and Bounded World, Op.cit, pp. 43-44.

(52) Rawls, J.; Political Liberalism, Op.cit, pp. 224 - 225.

(53) Ibid., p. 94.

(54) Estlund, D.; The Insularity of the Reasonable: Why Political Liberalism Must Admit the Truth," pp. 252-275, Ethics, Vol. 108, No. 2, 1998.

Raz, J.; "Facing Diversity: The Case of Epistemic Abstinence", Op.cit.

(55) Cohen, J.; "Truth and Public Reason", pp. 2-42, Philosophy \& Public Affairs, Vol. 37, No. 1, 2008.

(56) D'Agostino, F.; Free Public Reason; Making it Up As We Go, Oxford University Press, New York, 1996, pp. 30 - 31.

Nagel, T.; "Moral Conflict and Political Legitimacy", pp. 215- 240, Philosophy \& Public Affairs, Vol. 16, No. 3, 1987, pp. 218 - 219.

(57) Habermas, J.; Between Facts and Norms: Contributions to a Discourse Theory of Law and Democracy, Op.cit, p.339.

(58) Tulis, J. K \& Macedo, S.; The Limits of Constitutional Democracy, Princeton University Press, Princeton, U. S. A, 2010.

$$
\text { انظر أيضًا : n }
$$

Quong, J.; Liberalism without Perfection, Op.cit, pp. 261 - 273.

Doi: $10.12816 / 0051451$ 
(60) Quong, J.; Liberalism without Perfection, Op.cit, pp. 261 - 273.

(61) Tulis, J. K \& Macedo, S.; The Limits of Constitutional Democracy, Op.cit

(62) Rawls, J.; Political Liberalism, Op.cit, p. 217.

(63) Rawls, J.; Collected Papers, Op.cit, pp. 576 - 577

(70) Wall, S.; "Is Public Justification Self-Defeating?", pp. 385- 394, American Philosophical Quarterly, Vol. 39, No.4, 2002.

(71) Gaus, G.; The Order of Public Reason: A Theory of Freedom and Morality in a Diverse and Bounded World, Op.cit, pp. $277-228$.

(72) Estlund, D.; The Insularity of the Reasonable: Why Political Liberalism Must Admit the Truth," Op.cit.

(75) Rawls, J.; Political Liberalism, Op.cit, p. 94.

(76) Raz, J.; "Disagreement in Politics", pp. 25-52, The American Journal of Jurisprudence, Vol. 43, 1998, p. 42.

(77) Raz, J.; "Facing Diversity: The Case of Epistemic Abstinence", Op.cit, p. 23.

(78) Estlund, D.; The Insularity of the Reasonable: Why Political Liberalism Must Admit the Truth," Op.cit.

(79) Barry, B.; "John Rawls and the Search for Stability", pp. 874-915, Ethics, Vol. 105, No. 4, 1995, pp. $901-914$.

$$
\text { انظر أيضًا : }
$$

McCabe, D.; "Knowing About the Good", pp. 311-338, Ethics, Vol. 110, No. 2, 2002, pp. $316-324$.

Wall, S.; "Is Public Justification Self-Defeating ?", Op.cit, pp. 91 - 94.

Wenar, L.; "Political Liberalism: An Internal Critique", Op.cit, pp. 41 48.

(80) Quong, J.; Liberalism without Perfection, Op.cit, pp. 221 - 242.

(81) Mendus, S.; Impartiality in Moral and Political Philosophy, Oxford University Press, Oxford, U. S. A, 2002, pp. 26-28.

$$
\text { انظر أيضًا : }
$$

Rawls, J.; Political Liberalism, Op.cit, p. 150. 
(83) Rawls, J.; Political Liberalism, Op.cit, pp. 244 - 246.

Rawls, J.; Collected Papers, Op.cit, pp. 585 - 586.

(84) Horton, J.; "Rawls, Public Reason, and the Limits of Liberal Justification", pp. 5-23, Contemporary Political Theory, Vol. 2, No. 1, 2003.

$$
\text { انظر أيضًا : }
$$

de Marneffe, P.; "Rawls's Idea of Public Reason", Pacific Philosophical Quarterly, pp. 232-250, Vol. 75, No. (3/4), 1994.

Reidy, D.; "Rawls's Wide View of Public Reason: Not Wide Enough", pp. 49- 72, Res Publica, Vol. 6, No. 1, 2000.

Sandel, M.; Liberalism and the Limits of Justice: Second Edition, Cambridge University Press, Cambridge, U.S.A, 1998.

(85) Gaus, G.; Justificatory Liberalism: An Essay on Epistemology and Political Theory, Oxford University Press, Oxford, U.S.A, 1996, pp. $151-158$.

$$
\text { : انظر أيضًا }
$$

Schwartzman, M.; "The Completeness of Public Reason", pp. 191-220, Politics, Philosophy, \& Economics, Vol. 3, No. 2, 2004.

(89) Eberle, C.; Religious Conviction in Liberal Politics, Cambridge University Press, Cambridge, 2002.

Greenawalt, K.; Private Consciences and Public Reasons, Op.cit.

Smith, S. D.; The Disenchantment of Secular Discourse, MA: Harvard University Press Cambridge, 2010.

Stout, J; Democracy and Tradition, Op.cit.

Weithman, P.; Religion and the Obligations of Citizenship, Op.cit.

(90) Bohman, J.; "Deliberative Toleration", Op.cit.

Friedman, M.; "John Rawls and the Political Coercion of Unreasonable People", pp. 16-33, in The Idea of a Political Liberalism: Essays on John Rawls, V. Davion and C. Wolf (eds.), Rowman and Littlefield, Oxford, U. S. A, 2000. 